University of Rhode Island

DigitalCommons@URI

Open Access Master's Theses

2015

\title{
Longitudinal Study of Physical Functioning in Adults with Chronic Neurological Conditions
}

Marcia Kimberley Lyons

University of Rhode Island, kimlyons@aol.com

Follow this and additional works at: https://digitalcommons.uri.edu/theses

\section{Recommended Citation}

Lyons, Marcia Kimberley, "Longitudinal Study of Physical Functioning in Adults with Chronic Neurological Conditions" (2015). Open Access Master's Theses. Paper 639.

https://digitalcommons.uri.edu/theses/639

This Thesis is brought to you for free and open access by DigitalCommons@URI. It has been accepted for inclusion in Open Access Master's Theses by an authorized administrator of DigitalCommons@URI. For more information, please contact digitalcommons-group@uri.edu. 


\title{
LONGITUDINAL STUDY OF PHYSICAL FUNCTIONING
}

IN ADULTS WITH CHRONIC NEUROLOGICAL

\author{
CONDITIONS
}

BY

MARCIA KIMBERLEY LYONS

A THESIS SUBMITTED IN PARTIAL FULFILLMENT OF THE

REQUIREMENTS FOR THE DEGREE OF

MASTER OF SCIENCE

IN

KINESIOLOGY

UNIVERSITY OF RHODE ISLAND

2015 
MASTER OF SCIENCE THESIS

OF

MARCIA KIMBERLEY LYONS

\section{APPROVED:}

Thesis Committee:

Major Professor Matthew J. Delmonico

Leslie A. Mahler

Furong $\mathrm{Xu}$

Nasser H. Zawia DEAN OF THE GRADUATE SCHOOL 


\begin{abstract}
There is limited information in the literature comparing gait speed among individuals who are in the chronic stages of Parkinson's disease (PD), stroke and traumatic brain injury (TBI). The primary aim of this study was to examine the physical functioning of individuals with these chronic neurological conditions over a 12-month period assessed at baseline (time 1) and six month intervals (time 2, 3). This observational research study used descriptive statistics and to describe the physical functioning of individuals with PD, stroke and TBI and was part of a longitudinal study being conducted over five years to describe communication, dietary and physical activity behaviors of adults with neurological diagnoses. Seven community dwelling adults $(n=7)$ between the ages of 34 and 71 years completed the evaluations. The tests used to examine physical function included gait speed, repeated chair stands, short physical performance battery (SPPB), timed up and go (TUG), and the Physical Activity and Disability Scale (PADS). The results were analyzed for the cohort and divided into two groups for comparison: PD and acquired brain injury (ABI). ABI included people with the TBI and stroke diagnoses. Changes in gait speed were determined using analysis of covariance. A Pearson's product moment correlation coefficient was used to determine association between gait speed and physical function assessments. Statistical significance was set at $\mathrm{p}<0.05$. Analysis of covariance (ANCOVA) results showed a statistically significant decrease (i.e. improvement) in gait speed $(\mathrm{p}<0.03)$ for the ABI group over 12 months. Although not statistically significant, there was also a decrease in gait speed $(\mathrm{p}<0.10)$ for the PD group. The ANCOVA results also showed a statistically significant increase (i.e.
\end{abstract}


decline $)$ in the TUG test time of 3.33 seconds $(p=0.054)$ for the ABI group and increases in time for the PD group and cohort. Baseline gait speed for all participants correlated with the total SPPB score $r=-0.97, \mathrm{p}=0.001)$ and the TUG test $(r=0.97, \mathrm{p}$ $=0.001)$. Time 3 gait speed for all participants also correlated with the PADS score $(r$ $=-0.79, \mathrm{p}=0.06)$ in addition to the SPPB score $(r=-0.87, \mathrm{p}<0.01)$ and TUG test $(r=$ $0.96, \mathrm{p}<0.01)$. There was a statistically significant decrease in gait speed of adults with ABI measured three times in 12 months. Secondary findings include the significant decline in mobility in adults with ABI measured over 12 months. The significant relationship between gait speed and the physical function, mobility and physical activity scores was also a secondary finding. Future studies should consider interventions aimed at improving physical activity and fall and balance self-efficacy to explore the impact on gait speed in chronic neurological conditions. Future longitudinal research should also be conducted with a larger sample size and broader range of chronic neurological conditions to allow generalization of the study findings. 


\section{ACKNOWLEDGMENTS}

The funding for this study was provided by the University of Rhode Island Communicative Disorders Department. The study was conducted using a transdisciplinary approach and personnel were provided by the Departments of Communicative Disorders, Kinesiology and Nutrition and Food Sciences. I wish to thank each of the departments and the Longitudinal Study Team. Also, I extend my deepest gratitude to the participants for their time and efforts in expanding our knowledge. A special thanks goes to my major professor Dr. Matthew Delmonico and the primary investigator for the longitudinal study Dr. Leslie Mahler. Through their guidance and support, both Dr. Delmonico and Dr. Mahler were integral in the completion of my thesis. Finally, I would be remiss if I did not thank my husband for his patience over the past two years while I completed my graduate degree in Kinesiology and this thesis. The support of each department and individuals I mentioned has ultimately led to the advancement of knowledge concerning physical functioning in individuals who are in the chronic stages of Parkinson's disease, stroke and traumatic brain injury. 


\section{PREFACE}

This thesis is written to comply with the University of Rhode Island graduate school manuscript format. The thesis document contains one manuscript:

Longitudinal Study of Physical Functioning in Adults with Chronic Neurological

Conditions. The manuscript has been written in a form formatted for publication in the Disability and Health Journal. 


\section{TABLE OF CONTENTS}

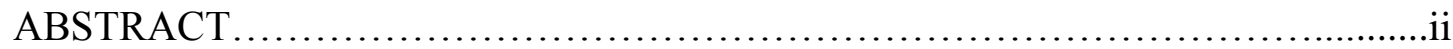

ACKNOWLEDGMENTS ...................................................

PREFACE............................................................

TABLE OF CONTENTS.................................................vi

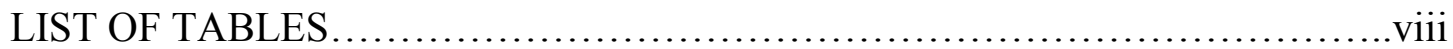

MANUSCRIPT: Longitudinal Study of Physical Functioning in Adults with Chronic

Neurological Conditions..................................................

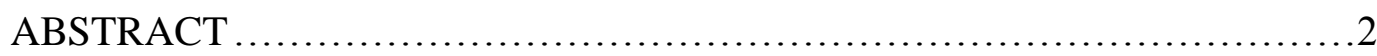

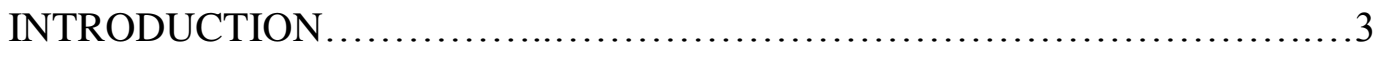

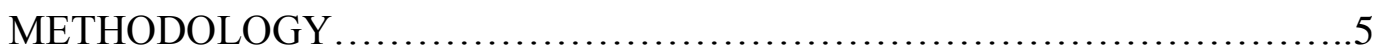

RESULTS..........................................................11

DISCUSSION ......................................................... 15

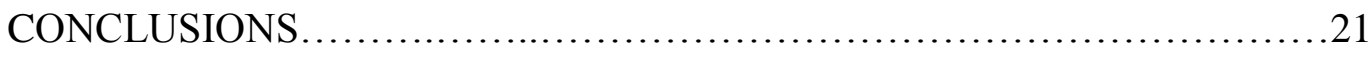

REFERENCES ........................................................22

TABLES AND FIGURES............................................. 25

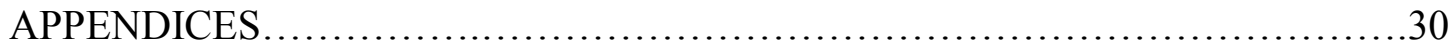

Appendix A: Review of the Literature.................................... 30

Appendix B: Extended Methodology ...................................56

Appendix C: Consent Form for Research..............................63

Appendix D: Short Physical Performance Battery (SPPB) ..................68

Appendix E: Timed Up and Go (TUG) Test..........................71 
Appendix F: Physical Activity and Disability Scale (PADS)

Appendix G: Repeatable Battery for the Assessment of Neuropsychological Status (RBANS) .80 


\section{LIST OF TABLES}

TABLE

PAGE

Table 1. Baseline Characteristics of the cohort and PD and ABI groups.................. 23

Table 2. Baseline, Time 2, Time 3 Data and Change in the Cohort and PD and ABI

Groups

Table 3. Gait Speed Time Changes Within Cohort, PD and ABI Groups and Between

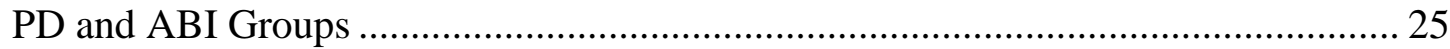

Table 4. TUG Changes within Cohort, PD and ABI Groups and Between PD and ABI

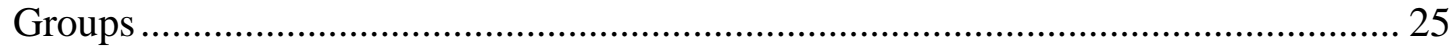

Table 5. Baseline, Time 2, Time 3 Data and Change for each Participant..............26 


\section{MANUSCRIPT}

\section{Longitudinal Study of Physical Functioning in Adults with Chronic Neurological Conditions}

Manuscript Type: Original Research

Authors: Marcia K. Lyons, M.S., M.H.A., R.N. ${ }^{\mathrm{b}}$, Furong Xu, Ph.D. ${ }^{\mathrm{b}}$, Ingrid E. Lofgren, Ph.D., M.P.H., R.D. ${ }^{\mathrm{c}}$, Matthew J. Delmonico Ph.D., M.P.H. ${ }^{\mathrm{b}}$, Leslie A. Mahler, Ph.D., C.C.C.-S.L.P. ${ }^{\mathrm{a}}$

Corresponding Author: Leslie A. Mahler ${ }^{a}$, 1mahler@uri.edu, (401) 874-2490

aDepartment of Communicative Disorders, University of Rhode Island, Independence Square I, Kingston, Rhode Island, 02881, USA

bepartment of Kinesiology, University of Rhode Island, Independence Square II, Kingston, Rhode Island, 02881, USA

${ }^{\mathrm{c}}$ Department of Nutrition and Food Sciences, University of Rhode Island, Ranger Hall, Kingston, Rhode Island, 02881, USA

Abstract word count: 248

Manuscript word count: 4180

Number of references: 32

Number of figures/tables: 5

Funding support: No funding was provided for this study.

Conflict of interest: We certify that no party having direct interest in the results of the research that support this article.

Acknowledgements: The authors would like to extend their gratitude to undergraduate research assistants from the Departments of Communicative Disorders, Kinesiology and Nutrition and Food Sciences at the University of Rhode Island, and to all of the participants for their commitment and involvement in the Longitudinal Study of Communication, Nutrition and Physical Activity.

This manuscript was formatted and prepared for publication in the Disability and Health Journal. 


\begin{abstract}
Background: There is limited information assessing gait speed over time in the chronic stages of Parkinson's disease (PD) and acquired brain injury (ABI).

Hypothesis: There will be no change in gait speed in adults with chronic neurological conditions measured three times over 12 months.

Methods: An observational research design was used to examine physical functioning in seven participants over 12 months. Physical status was assessed using the short physical performance battery (SPPB), timed up and go (TUG), and Physical Activity and Disability Scale (PADS). Cognitive function was examined using the Repeatable Battery for the Assessment of Neuropsychological Status (RBANS). Data were analyzed using descriptive statistics, analysis of covariance, and Pearson's correlation coefficients.
\end{abstract}

Results: ANCOVA results showed a decrease in gait speed within the ABI group (p $<0.03)$ and within the PD group $(\mathrm{p}<0.10)$ along with an increase in the TUG time of 3.33 seconds $(\mathrm{p}=0.054)$ for the $\mathrm{ABI}$ group and increases in time for the PD group and cohort. Gait speed at 12 months correlated with the PADS score $(r=-0.79, \mathrm{p}=0.06)$, SPPB score $(r=-0.87, \mathrm{p}<0.01)$ and TUG test $(r=0.96, \mathrm{p}<0.01)$ for the cohort.

Conclusions: There was a statistically significant improvement in gait speed of adults with ABI measured over 12 months. Secondary findings include 1) a significant decline in mobility in adults with ABI and 2) the significant relationship between gait speed and the physical function, mobility and physical activity scores.

Keywords. Parkinson's disease, traumatic brain injury, stroke, gait speed, physical function 


\section{INTRODUCTION}

Traumatic brain injury (TBI) and stroke affect 1.7 million and 795,000 Americans in the United States (US) each year respectively ${ }^{1,2}$. At the same time, one million people in the US are living with Parkinson's disease ${ }^{3}$. Parkinson's disease (PD), TBI and stroke can result in disabilities that include decreased ability to communicate, difficulty maintaining a healthy diet, and reduced levels of physical activity and physical function. The TBI and stroke diagnoses are both considered acquired brain injury (ABI).

Individuals with $\mathrm{ABI}$ and $\mathrm{PD}$ are particularly vulnerable to the damaging effects of physical inactivity and face declines in balance, coordination, strength, mobility and overall quality of life ${ }^{4}$. Gait speed, coined the sixth vital sign, has been suggested to correlate with functional ability and balance confidence and aids in determining rehabilitation potential and fall risk ${ }^{5}$. Additionally, gait speed improvement has been linked to enhanced quality of life $e^{5,6}$ and is critical to maintaining community ambulation or independent mobility outside the home ${ }^{7}$.

There is limited information in the literature about gait speed in individuals who are in the chronic stages of $\mathrm{PD}$ and $\mathrm{ABI}^{8}$. There is even less information that jointly examines gait speed in persons with PD or ABI. Therefore, the primary aim of the study was to examine the physical functioning of individuals with chronic neurological conditions of stroke and ABI over a 12-month period assessed at six month intervals. Specifically, the null hypothesis was that there will be no change in gait speed of adults with chronic neurological conditions measured three times over 12 months. Independent predictors of changes in gait speed including the short physical 
performance battery (SPPB) total score, repeated chair stands, timed up and go (TUG) test, Physical Activity and Disability Scale (PADS) score, and Repeatable Battery for the Assessment of Neuropsychological Status (RBANS) delayed memory index were also explored. 


\section{METHODOLOGY}

\section{Study Design}

This observational research study used surveys and quantitative evaluations to assess the physical functioning of individuals with PD and ABI. The study lasted 12 months and consisted of three evaluations: baseline, time 2, and time 3 . The baseline measures were collected when the participants joined the study. Time 2 measures were collected at six months and time 3 measures were collected at 12 months. The study was part of an Institutional Review Board (IRB) approved longitudinal study at the University of Rhode Island being conducted over five years to describe communication, dietary and physical activity behaviors of adults with neurological diagnoses (Longitudinal Study of Communication, Nutrition and Physical Activity, IRB HU1314-006).

\section{Participants}

The longitudinal study participants were required to be 1) diagnosed with PD, TBI or stroke, 2) determined to be medically stable by a neurologist, 3) between the ages of 18 and 85 years, and 4) sign an informed consent form. They were recruited equally in an attempt to represent the demographics of Rhode Island. Rolling admission was accomplished through word of mouth and by sending brochures to local physicians, hospitals and support groups. Of the 15 participants currently in the study, seven completed three evaluations in the 12-month period of this study. 


\section{Outcome Measures}

The independent variables in this study were the neurological conditions. Gait speed, a component of the SPPB, was the primary outcome measure. Changes in other measures of physical function including the SPPB score, repeated chair stands, and TUG test were examined to determine if there was a relationship or association with changes in gait speed. Dependent variables including the PADS score and RBANS delayed memory index were also analyzed to determine if there is a relationship with changes in gait speed. Following is a description of the instruments and techniques used to collect these data along with the anthropometric data.

Physical Functioning Assessment. The SPPB instrument is widely used to assess lower extremity function and takes fewer than ten minutes to complete. It includes using three low participant-burden activities to assess participant's physical functioning: gait speed, standing balance, and time to rise from a chair and return to the seated position. The score range for each subtest is zero to four points with a maximum cumulative score of 12 points $^{9,10}$. Each test was timed using a hand held stopwatch.

Gait speed was measured by having the participants walk at their usual pace on a measured and taped course. The distance for this study was four meters and the participants began and ended the test in the standing position. Additional unobstructed space was be marked at the end of the walking course and participants were instructed to continue walking through the finish line to prevent deceleration in pace. The test was repeated and the faster of the two tests was used in the data analysis ${ }^{9}$. 
Participants performed side-by-side, semi-tandem (heel of one foot by big toe of other foot) and tandem (feet aligned heel to toe) foot positions for the standing balance tests. They were assisted to the standing position as needed and timed when they were standing independently. The timing ended at 10 seconds or earlier if the participant lost balance by moving their feet or grasping for support ${ }^{9}$.

Five-time repeated chair stands were performed to test lower extremity strength and endurance. A chair was placed against the wall. Participants were instructed to fold their arms over their chests and attempt one stand. If successful, participants were asked to stand and sit as quickly as possible without the use of their arms for five repetitions. Participants were timed from the point when they arose from the chair, stood five times and returned to the seated position 9 .

A TUG test was also conducted. The TUG test is a valid predictor of falls and mobility and measures the time in seconds required for an individual to rise from a chair, walk a prescribed distance, return and sit down in the chair ${ }^{11}$. The TUG test used in this study was conducted according to a standardized protocol where participants were asked to rise from a chair, walk forward four meters at their usual walking pace, turn 180 degrees around a cone, walk four meters back to the chair, and finally sit down. The test was repeated and the better of the two tests was used in the data analysis. The test was timed using a hand held stopwatch.

Physical Activity and Disability Scale. The PADS, a self-reported survey, provides a reliable and valid measure of physical activity for persons with disabilities or chronic health conditions and has been reported to detect intervention related changes in physical activity ${ }^{12}$. It is composed of six subscales: exercise, leisure time, 
physical activity, general activity, therapy, employment/school and wheelchair users and takes approximately 20 minutes to complete. The survey is known to discriminate between different levels of activity and participants report that it enables them to give an accurate description of their level of exercise ${ }^{4}$. The participants were interviewed to collect the data for the survey. The scores were calculated using a standardized scoring tool.

Repeatable Battery for the Assessment of Neuropsychological Status (RBANS). The RBANS consists of 12 subtests and takes less than 30 minutes to administer. It is used to measure and yields index scores in immediate and delayed memory, language, attention and visuospatial/ constructional abilities. The results can be used to assess cognitive function in individuals from 20-89 years in age ${ }^{13}$. This study explored whether the delayed memory index is an independent predictor of gait speed in individuals with chronic neurologic conditions. The delayed memory index includes four subsets (list recall, list recognition, story recall, and figure recall) that measure recall and recognition ${ }^{13}$.

Anthropometric measures. The anthropometric measures included height, weight, body mass index (BMI) and body composition. Height and weight were measured using a balance beam scale (Detecto, Webb City, MO). The scale was zeroed prior to testing and participants were measured standing erect with their backs to the height measuring rod and in bare feet. The measurements were entered into the formula kilograms of body weight divided by height in meters squared $\left(\mathrm{kg} / \mathrm{m}^{2}\right)$ to determine BMI. 
Body composition was measured using a foot to foot bioelectrical impedance analysis (BIA) device (Tanita BC-534 Inner Scan Body Composition Monitor, Tanita Corporation of America, Inc, Arlington Heights, IL). The BIA device is a portable battery powered foot-to-foot BIA device that resembles a bathroom scale. It uses a very low electrical current to estimate percent body fat ${ }^{14}$. Participants were measured standing erect with bare feet on the analyzer foot pads. The individual's age, gender, height, weight, and activity level was entered into the analyzer prior to standing on the foot pads.

\section{Statistical Analysis}

A sample size was calculated using SAS statistical software (SAS Institute Inc., version 9.2, Cary, NC) and the potential change in gait speed and standard deviation were based on previous research ${ }^{15}$. The sample size calculations were founded on an alpha of 0.05 , a power of $80 \%$, expected within group difference of $0.18 \mathrm{~m} / \mathrm{s}$ for gait speed, and a within group standard deviation of $0.12 \mathrm{~m} / \mathrm{s}$. Based on the criteria, the one group sample size was approximately six participants.

Data analyses were conducted using SAS statistical software (SAS Institute Inc., version 9.2, Cary, NC) and Microsoft Excel (Microsoft Corporation, version 2013, Redmond, WA). Mean values for demographic and descriptive characteristics were calculated for all participants and the PD and ABI groups and are represented as continuous variables. Normality of the data was determined using the Shapiro-Wilk test. An outlier analysis was performed for gait speed using the mean plus or minus three standard deviations. A repeated measures analysis of covariance (ANCOVA) 
was used to examine changes in gait speed for the cohort and the between the PD and ABI groups over the course of the study. The covariate was the baseline measure for each group. Statistical significance was set at $\mathrm{p}<0.05$. Additionally, correlations were conducted to quantify the relationship between gait speeds and the SPPB, TUG, PADS and RBANS delayed memory index scores. A Pearson's product moment correlation coefficient was calculated to evaluate the relationships ${ }^{16}$. 


\section{RESULTS}

The results were reviewed for the cohort and divided into two groups for comparison: PD and ABI. A Shapiro-Wilk test supported the normality of the data at baseline $(\mathrm{p}=0.28)$ and time $3(\mathrm{p}=0.30)$. Demographic characteristics, anthropometric measures and indicators of physical functioning, physical activity and cognitive function for each group are summarized in Table 1. The participants included six males and one female and were between the ages of 34 and 71 years. The mean age for the PD group was 67.5 years and the ABI group was 43 years. All participants were community dwelling adults living with PD or ABI for greater than three years. Four participants were diagnosed with PD and three were diagnosed with an ABI. Of the three ABI participants, one was diagnosed with stroke, one with TBI and one was diagnosed with both stroke and TBI. There were statistically significant differences $(\mathrm{p} \leq 0.05)$ between the PD and ABI groups in age, SPPB total, gait speed and the TUG test.

Table 2 displays the changes that occurred from the baseline to the time 3 measurements in the cohort, PD and ABI groups. Each of the groups experienced a decrease in weight, body fat, BMI and gait speed. There was also an increase in the TUG time and the PADS score for each group. The total SPPB score increased for the $\mathrm{ABI}$ and decreased for the cohort and PD groups. Contributing to this score was the decrease in the chair stand time for the ABI group and increase in the cohort and PD groups. The RBANS delayed memory index decreased in the PD group and increased in the cohort and $\mathrm{ABI}$ group. 
The ANCOVA results for the gait speed changes are displayed in Table 3. The results showed a statistically significant decrease (i.e. improvement) in gait speed ( $\mathrm{p}=$ 0.032) for the ABI group. Although not statistically significant, there was also a decrease in gait speed for the PD group $(\mathrm{p}=0.099)$ and cohort. The difference between the groups was not significant.

The ANCOVA results displayed in Table 4 also showed a statistically significant increase (i.e. decline) in the TUG test time of 3.33 seconds $(p=0.054)$ for the ABI group and increases in time for the PD group and cohort. The difference between the groups was not significant.

Baseline gait speed for all participants correlated with the total SPPB score $(r=-$ $0.97, \mathrm{p}<0.001)$ and the TUG test $(r=0.97, \mathrm{p}<0.001)$. No significant correlation was found between baseline gait speed and the chair stands, PADS score, or RBANS Delayed Memory Index. Time 3 gait speed for all participants also correlated with the PADS score $(r=-0.79, \mathrm{p}=0.06)$ in addition to the SPPB score $(r=-0.87, \mathrm{p}<0.01)$ and TUG test $(r=0.96, \mathrm{p}<0.01)$.

Baseline, time 2 and time 3 performance measures for each participant are reported in Table 7. Each participant attended the three evaluations; however, two participants were not able to complete the repeated chair stands, one participant was not able to complete the TUG test, and one participant did not complete the PADS instrument.

\section{Physical functioning (SPPB)}

Baseline SPPB scores ranged from 5 - 11. At time 3, three of the participants increased their score, one remained the same and three participants had a lower score. 
The total score was lowest for the two participants that could not complete the repeated chair stands.

\section{Gait Speed}

Baseline gait speeds for the four meter test ranged from 4.16 to 9.68 seconds or 0.41 to $0.96 \mathrm{~m} / \mathrm{s}$. All of the participants demonstrated an increase in the $\mathrm{m} / \mathrm{s}$; however, six of the seven participants demonstrated a meaningful change that ranged from 0.11 to $0.48 \mathrm{~m} / \mathrm{s}$.

\section{Lower Extremity Performance (Repeated Chair Stands)}

Two participants were unable to complete the repeated chair stands and two participants increased the time required to complete the test suggesting a decline in lower extremity performance. Three of the participants decreased the time that they required to complete the repeated chair stands.

\section{Mobility (TUG Test)}

Baseline scores for the TUG test ranged from 8.16 seconds to 18.31 seconds or 1.02 to 2.29 seconds per meter respectively. One participant was unable to complete the test at time 3, one participant experienced a minimal decrease in score and the remaining five participants demonstrated an increase in the time needed to complete the test.

\section{Physical Activity (PADS)}

Four of the seven participants improved from their baseline PADS score during the course of the study. One participant did not complete the survey at time 3; however, the participant did show improvement at time 2. Baseline scores ranged 
from 26.4 to 310.9 . Scores at time 3 ranged from -21 to 302.2 with a variable change of -6 to $705 \%$.

\section{Recall and Recognition (RBANS Delayed Memory Index)}

The RBANS scores ranged from 40 to 102 at baseline with a variable change of 8 to $21 \%$ at the time 3 evaluation. No correlation was observed between gait speed and the delayed memory index in the cohort. 


\section{DISCUSSION}

To our knowledge, this is the first study to compare gait speed in adults with PD and $\mathrm{ABI}$ in the chronic stages of recovery. The primary finding of the study rejects the null hypothesis that there will be no change in gait speed of adults with chronic neurological conditions measured three times in 12 months. The results indicated that there was a decrease (i.e. improvement) in gait speed in adults with chronic neurological conditions and statistically significant improvements in participants with ABI measured three times in 12 months.

The time required to complete the 4-m gait speed test improved for the ABI group by 2.53 seconds $(\mathrm{p}=0.03)$ and for the PD group by 0.85 seconds $(\mathrm{p}=0.10)$. Although not statistically significant, the time also improved for the cohort by 1.57 seconds $(\mathrm{p}=$ 0.38). The improvement in walking speed was $0.17 \mathrm{~m} / \mathrm{s}$ for the PD group, $0.26 \mathrm{~m} / \mathrm{s}$ for the $\mathrm{ABI}$ group and $0.23 \mathrm{~m} / \mathrm{s}$ for the cohort. The improvements exceed the minimally meaningful change for the 4-m gait speed test has been reported by Kwon et al. as $0.03-0.05 \mathrm{~m} / \mathrm{s}^{17}$ suggesting that the improvements experienced by the study cohort may have important implications in community ambulation.

Gait speed has been reported to be the most efficient predictor of household and community ambulation, a significant determinant of community ambulation, and a powerful indicator of function and prognosis post-stroke ${ }^{18-20}$. The gait speed cut-off points for community ambulation have been reported in several articles and range from $0.66 \mathrm{~m} / \mathrm{s}$ for community ambulation ${ }^{19}$ to $0.8 \mathrm{~m} / \mathrm{s}$ for full community ambulation $^{20}$. The gait speed for the each of the groups exceeded the cut-off point of $0.66 \mathrm{~m} / \mathrm{s}$ and the threshold for full community ambulation (Cohort $0.90 \mathrm{~m} / \mathrm{s}$, PD 1.0 
$\mathrm{m} / \mathrm{s}$, ABI $0.8 \mathrm{~m} / \mathrm{s}$ ) at the time 3 evaluation. The individual scores ranged from 0.66 $\mathrm{m} / \mathrm{s}$ to $1.08 \mathrm{~m} / \mathrm{s}$ for the participants with PD and 0.63 to $0.92 \mathrm{~m} / \mathrm{s}$ for the participants with ABI.

Although gait speed improved for all participants, the time required to complete the mobility test increased resulting in a performance decline for each of the groups and participants. The TUG times in $\mathrm{m} / \mathrm{s}$ for the cohort, $\mathrm{PD}$ and $\mathrm{ABI}$ groups equated to $0.55 \mathrm{~m} / \mathrm{s}, 0.76 \mathrm{~m} / \mathrm{s}$, and $0.43 \mathrm{~m} / \mathrm{s}$, respectively. This may have resulted from the 180 degree turn in the TUG and deficits in balance, coordination and self-efficacy that are experienced by individuals with chronic neurological conditions. The declines are consistent with a longitudinal study by van de Port et al. ${ }^{21}$ that suggested that mobility is not stable, but time dependent with approximately 20 percent of the participants experiencing decreased mobility from one to three years post-stroke ${ }^{21}$. They are also similar to a study where individuals with chronic TBI were found to exceed the MDC for walking speed with smaller gains in the TUG test. Gains that were maintained at the three month post intervention were attributed to improvements in gait speed, mobility, balance and fall self-efficacy ${ }^{22}$.

The mean ages of the PD and $\mathrm{ABI}$ groups were also considered as confounding variables on the gait speed and mobility results. The mean age for the PD group was 24.5 years greater than the mean age of the ABI group. Thus, this could have had an effect on these results as the aging process is accompanied by sarcopenia or a gradual loss of skeletal muscle mass and function that typically begins after age 30 that is associated with worsened physical functioning ${ }^{23}$. In a three year study by Trombetti et al. ${ }^{24}$, participants with age-associated declines in muscle mass, strength, power and 
physical performance were found to have decreased SPPB scores and increased walk times $^{24}$. The PD group (mean age 67.5, SD 3.8) had higher scores on the SPPB and walked faster than the ABI group (mean age 43, SD 13) over the course of the study. However, the ABI group exhibited greater improvements in their SPPB scores and walking speed at time 3 possibly due to their younger age.

Major findings of the study also included the statistically significant relationship identified between gait speed at baseline and time 3, and the total SPPB score and TUG test for all participants. At time 3, there was also significant correlation PADS score. The PADS has been reported to detect changes in physical activity in persons with disabilities and chronic health conditions ${ }^{12}$. There was an increase in the PADS score for each group. Although this study did not involve an intervention, the majority of the participants were engaged in physical therapy, occupational therapy or physical training and an increase in physical activity was reported via the PADS interview for five of the seven participants. The increase in physical activity may have contributed to the previously mentioned improvement in gait speed times, but this is merely speculative.

A study by Duff et al. ${ }^{25}$ reported significant partial correlations $(\mathrm{p}<0.01)$ controlling for age, gender and education between gait times and the RBANS total score and component indexes (total $r=-0.25$, immediate memory $r=-0.20$, visuospatial/constructional $r=-0.18$, language $r=-0.12$, attention $r=-0.21$, delayed memory $r=-0.15)^{25}$. A recent study reported that poorer short term memory assessed using a 10 word recall test (immediate and delayed recall) was associated with slower gait speed in community dwelling individuals 50 years and older ${ }^{26}$. However, no 
correlation was observed between gait speed and the RBANS delayed memory index in the cohort.

The SPPB was established by Guralnik et al. as a disability measure for older adults $^{9}$. In 2010, Vazzana et al. ${ }^{27}$ defined impaired mobility as a SPPB score of less than $10^{27}$. The component tests provide an indication of physical function including gait speed, balance and lower extremity performance. All total scores for the cohort and $\mathrm{PD}$ and $\mathrm{ABI}$ groups were 10 or less suggesting impaired mobility. The scores ranged from 8.0 to 8.8 at time 3 with the total SPPB score increasing for the ABI group and decreasing for the cohort and PD groups. Contributing to the scores was the improvement in the repeated chair stand time for the ABI group and decline in the cohort and PD groups. A minimally meaningful change for the SPPB has been reported by Kwon et al. as $0.3-0.8$ points ${ }^{17}$. The total SPPB score improved clinically for the ABI group by 1.3 points for a mean total score of 8.0. The score declined for the PD group by 1.2 points and the cohort by 0.2 points for mean total scores of 8.8 and 8.4 , respectively.

The longitudinal findings of this study are an improvement to the existing knowledge and will contribute to identifying the natural progression of disability in the PD and ABI populations. Limited longitudinal studies are available in the literature that evaluated physical functioning in chronic neurological conditions and those found primarily concern the stroke population. For example, a longitudinal study by van de Port et al. ${ }^{21}$ focused on deterioration of mobility from one to three years post-stroke used a self-reported mobility index consisting of 14 questions and one observation to assess mobility ${ }^{21}$. The present study used objective performance 
measures to assess gait and mobility. Peters et al. ${ }^{22}$, studied balance, mobility and gait speed in individuals with chronic TBI. The study involved task specific training to address balance, gait, strength and coordination. Evaluations were performed at baseline, after 10 exercise sessions and 20 exercise sessions. A follow up evaluation was performed at three months and the gait speed and mobility gains were maintained by the participants ${ }^{22}$; however, no further evaluations were conducted.

Limitations of the study included the small sample size, multiple examiners, the participants being exposed to different medical interventions during the study (physical therapy, occupational therapy, physical training) and the effects of repeated testing. The small sample size limited the ability to detect statistical significance and the generalizability of the results to individuals with PD, TBI and stroke. Although there were multiple examiners, a study strength included using defined protocols and trained observers for each of the tests. For the self-reported physical activity survey, interviews were used to obtain the information and the examiner was able to rephrase questions or ask additional questions to clarify responses. As part of this survey, information was also collected on the time each participant spent in therapy or physical training and the activities that resulted in an increased PADS score. Repeated testing could be also be seen as a threat to internal validity as individuals become familiar with the test items and perform better on subsequent tests; however, periodic evaluations over time were also a strength of the 12-month study ${ }^{28}$.

The key barriers to adopting physical activity include self-efficacy; fear of falling; and disability, balance and environmental concerns ${ }^{29-32}$. Although not examined in this study, evaluating these behaviors in future research may provide additional insight 
into the barriers that result in reduced levels of physical activity in the PD, TBI and stroke populations. Additionally, future research should expand recruitment across the three conditions, to compare differences between PD, TBI and stroke, rather than just PD and ABI. Future longitudinal studies should consider adding an intervention designed to ameliorate gait speed, mobility and self-efficacy and monitor the long term changes in physical function. 


\section{CONCLUSIONS}

In summary, this is the first study to compare gait speed in adults with PD and $\mathrm{ABI}$ in the chronic stages of recovery. The results indicated that there was a statistically significant improvement in gait speed of adults with ABI over the 12month period studied. Secondary findings included the significant decline in mobility in adults with $\mathrm{ABI}$ measured three times in 12 months and the relationship between gait speed and the physical function, mobility and physical activity scores. Future studies should consider interventions aimed at improving physical activity and fall and balance self-efficacy to explore the impact on gait speed in chronic neurological conditions. Future longitudinal research should be conducted with a larger sample size and broader range of chronic neurological conditions to verify the study findings. 


\section{REFERENCES}

${ }^{1}$ Faul M, Xu L, Wald MM. Traumatic brain injury in the United States: emergency department visits, hospitalizations, and deaths. Centers Dis Control Prev Natl Cent Inj Prev Control. 2010

${ }^{2}$ Go AS, Mozaffarian D, Roger VL, et al. Heart Disease and Stroke Statistics - 2014 Update: A Report from the American Heart Association; 2014.

${ }^{3}$ Parkinson's Disease Foundation (PDF). (2014) Understanding Parkinson's. http://www.pdf.org/. Accessed April 21, 2014.

${ }^{4}$ Kayes NM, Schluter PJ, McPherson KM, Taylor D, Kolt GS. The Physical Activity and Disability Survey -- Revised (PADS-R): an evaluation of a measure of physical activity in people with chronic neurological conditions. Clin Rehabil. 2009;23(6):534543.

${ }^{5}$ Fritz S, Lusardi M. White paper: "walking speed: the sixth vital sign". J Geriatr Phys Ther. 2009;32(2):46-49.

${ }^{6}$ Middleton A, Fritz S, Lusardi M. Walking speed: the functional vital sign. $J$ of Aging and Physical Activity. 2015;23(2), 314-322.

${ }^{7}$ Andrews AW, Chinworth SA, Bourassa M, Garvin M, Benton D, Tanner S. Update on distance and velocity requirements for community ambulation. J Geriatr Phys Ther. 2010;33(3):128-134

${ }^{8}$ Mahler L.A. Longitudinal Study of Communication, Nutrition and Physical Activity. (Unpublished Research Project Proposal). University of Rhode Island, Kingston, RI. 2013.

${ }^{9}$ Guralnik JM, Simonsick EM, Ferrucci L, et al. A short physical performance battery assessing lower extremity function: association with self-reported disability and prediction of mortality and nursing home admission. J Gerontol. 1994;49(2):M85M94.

${ }^{10}$ Stookey AD, Katzel LI, Steinbrenner G, Shaughnessy M, Ivey FM. The short physical performance battery as a predictor of functional capacity after stroke. J Stroke Cerebrovasc Dis. 2014;23(1):130-135.

${ }^{11}$ Whitney JC, Lord SR, Close JCT. Streamlining assessment and intervention in a falls clinic using the Timed Up and Go Test and Physiological Profile Assessments. Age Ageing. 2005;34(6):567-571. 
${ }^{12}$ Rimmer JH, Riley BB, Rubin SS. A new measure for assessing the physical activity behaviors of persons with disabilities and chronic health conditions: The physical activity and disability survey. Am J Heal Promot. 2001;16(1):34-45.

${ }^{13}$ Randolph C. Repeatable Battery for the Assessment of Neuropsychological Status: Examiner's Manual. San Antonio, TX: The Psychological Corporation, 2012.

${ }^{14}$ Ritchie JD, Miller CK, Smiciklas-Wright H. Tanita foot-to-foot bioelectrical impedance analysis system validated in older adults. J Am Diet Assoc. 2005;105(10):1617-1619.

${ }^{15}$ Fulk GD, Echternach JL. Test-retest reliability and minimal detectable change of gait speed in individuals undergoing rehabilitation after stroke. J Neurol Phys Ther. 2008;32(1):8-13.

${ }^{16}$ Vincent WJ, Weir JP Statistics in Kinesiology. (4th Ed.). Champaign, IL: Human Kinetics, 2012. Print.

${ }^{17}$ Kwon S, Perera S, Pahor M, et al. What is a meaningful change in physical performance? Findings from a clinical trial in older adults (The LIFE-P study). J Nutr Heal Aging. 2009;13(6):538-544.

${ }^{18}$ Perry J, Garrett M, Gronley JK, Mulroy SJ. Classification of walking handicap in the stroke population. Stroke. 1995;26(6):982-989.

${ }^{19}$ van de Port IG, Kwakkel G, Lindeman E. Community ambulation in patients with chronic stroke: How is it related to gait speed? J Rehabil Med. 2008;40(1):23-27.

${ }^{20}$ Schmid A, Duncan PW, Studenski S, et al. Improvements in speed-based gait classifications are meaningful. Stroke. 2007;38(7):2096-2100.

${ }^{21}$ van De Port IGL, Kwakkel G, Van Wijk I, Lindeman E. Susceptibility to deterioration of mobility long-term after stroke: A prospective cohort study. Stroke. 2006;37(1):167-171.

${ }^{22}$ Peters DM, Jain S, Liuzzo DM, et al. Individuals with chronic traumatic brain injury improve walking speed and mobility with intensive mobility training. Arch Phys Med Rehabil. 2014;95(8):1454-1460.

${ }^{23}$ Kostek MC, Delmonico MJ. Age-related changes in adult muscle morphology. Curr Aging Sci. 2011;4(3):221-33. 
${ }^{24}$ Trombetti A, Reid KF, Hars M, et al. Age-associated declines in muscle mass, strength, power, and physical performance: impact on fear of falling and quality of life. Osteoporos Int. 2015.

${ }^{25}$ Duff K, Mold JW, Roberts MM. Walking speed and global cognition: results from the OKLAHOMA Study. Neuropsychol Dev Cogn B Aging Neuropsychol Cogn. 2008;15(1):31-39.

${ }^{26}$ Killane I, Donoghue OA, Savva GM, Cronin H, Kenny RA, Reilly RB. Relative Association of Processing Speed, Short-Term Memory and Sustained Attention With Task on Gait Speed: A Study of Community-Dwelling People 50 Years and Older. Journals Gerontol Ser A Biol Sci Med Sci. 2014;69(11):1407-1414.

${ }^{27}$ Vazzana R, Bandinelli S, Lauretani F, et al. Trail making test predicts physical impairment and mortality in older persons. J Am Geriatr Soc. 2010;58(4):719-723.

${ }^{28}$ Thomas JR, Nelson JK, Silverman SJ. Research Methods in Physical Activity. (6 ${ }^{\text {th }}$ Ed.). Champaign, IL: Human Kinetics, 2011. Print.

${ }^{29}$ Driver S, Ede A, Dodd Z, Stevens L, Warren AM. What barriers to physical activity do individuals with a recent brain injury face? Disabil Health J. 2012;5(2):117-125.

${ }^{30}$ Elbers RG, Van Wegen EEH, Verhoef J, Kwakkel G. Is gait speed a valid measure to predict community ambulation in patients with Parkinson's disease? J Rehabil Med. 2013;45(4):370-375.

${ }^{31}$ Ellis T, Cavanaugh JT, Earhart GM, et al. Factors Associated With Exercise Behavior in People with Parkinson Disease. Phys Ther. 2011;91(12), 1838-1848.

${ }^{32}$ Schmid AA, Van Puymbroeck M, Altenburger PA, et al. Balance and balance selfefficacy are associated with activity and participation after stroke: A cross-sectional study in people with chronic stroke. Arch Phys Med Rehabil. 2012;93(6):1101-1107. 


\section{TABLES}

Table 1: Baseline Characteristics of the Cohort and PD and ABI groups.

\begin{tabular}{|l|c|c|c|c|}
\hline & All (n=7) & PD $(\mathbf{n = 4})$ & ABI (n=3) & P-value \\
\hline Age (years) & $57.0(15)$ & $67.5(3.8)$ & $43.0(13)$ & 0.015 \\
\hline Months Elapsed & $128.4(80.7)$ & $80.8(57)$ & $192(63.5)$ & 0.059 \\
\hline Gender & & & & 0.429 \\
\hline Men & 6 & 4 & 2 & \\
\hline Women & 1 & 0 & 1 & \\
\hline Height (cm) & $173.7(7.1)$ & $172.4(6.6)$ & $175.5(8.8)$ & 0.615 \\
\hline Weight (kg) & $81.8(11.4)$ & $80.6(11.9)$ & $83.4(13.0)$ & 0.783 \\
\hline Body Fat (\%) & $28.0(5.6)$ & $26.7(3.4)$ & $30.7(10.0)$ & 0.466 \\
\hline BMI (kg/m $)$ & $27.0(2.1)$ & $27(2.7)$ & $26.9(1.6)$ & 0.960 \\
\hline SPPB (total points) & $8.6(2.1)$ & $10(.82)$ & $6.7(1.5)$ & 0.013 \\
\hline $\begin{array}{l}\text { SPPB Gait Speed } \\
\text { (seconds) }\end{array}$ & $6.0(2.0)$ & $4.8(.88)$ & $7.6(2.0)$ & 0.050 \\
\hline $\begin{array}{l}\text { SPPB Chair Stand } \\
\text { (seconds) }\end{array}$ & $13.2(2.0)$ & $13.4(2.44)$ & $12.9(0.9)$ & 0.812 \\
\hline TUG Test (seconds) & $12.4(3.7)$ & $10.1(1.8)$ & $15.4(3.5)$ & 0.045 \\
\hline PADS score & $117.3(95.0)$ & $\begin{array}{c}137.6 \\
(118.2)\end{array}$ & $90.2(64.6)$ & 0.563 \\
\hline $\begin{array}{l}\text { RBANS Delayed } \\
\text { Memory score }\end{array}$ & $74(27.0)$ & $75(31.9)$ & $72.7(25.8)$ & 0.922 \\
\hline
\end{tabular}

All data are expressed as means with (standard deviations). Exception - gender P-value was calculated using an unpaired t-test and represents the between PD and ABI group differences. P-value for gender was calculated using a Fisher's Exact Test.

SPPB (4m walk, balance, repeated chair stands) - physical function

SPPB Gait Speed -4 meter walk measured in seconds SPPB Chair Stand - repeated chair stands measured in seconds TUG Test -8 meter mobility test measured in seconds PADS score - physical activity level RBANS delayed memory index (list recall, list recognition, story recall, and figure recall) - recall and recognition 
Table 2: Baseline, Time 2, Time 3 Data and Change in the Cohort and PD and ABI Groups

\begin{tabular}{|c|c|c|c|c|}
\hline Dependent Variable & All $(n=7)$ & PD $(n=4)$ & $\operatorname{ABI}(n=3)$ & P-value \\
\hline \multicolumn{5}{|l|}{ SPPB (total points) } \\
\hline Baseline & 8.6 & 10.0 & 6.7 & 0.013 \\
\hline Time 2 & 8.7 & 9.8 & 7.3 & \\
\hline Time 3 & 8.4 & 8.8 & 8.0 & 0.786 \\
\hline Change & $-2 \%$ & $-12 \%$ & $19 \%$ & \\
\hline \multicolumn{5}{|l|}{ SPPB Gait Speed (seconds) } \\
\hline Baseline & 6.0 & 4.8 & 7.6 & 0.050 \\
\hline Time 2 & 4.8 & 3.6 & 6.3 & \\
\hline Time 3 & 4.5 & 4.0 & 5.1 & 0.325 \\
\hline Change & $-25 \%$ & $-17 \%$ & $-33 \%$ & \\
\hline \multicolumn{5}{|c|}{ SPPB Chair Stand (seconds) } \\
\hline Baseline & 13.2 & 13.4 & 12.9 & 0.812 \\
\hline Time 2 & 14.6 & 12.5 & 16.6 & \\
\hline Time 3 & 13.3 & 14.2 & 12.0 & 0.484 \\
\hline Change & $1 \%$ & $6 \%$ & $-7 \%$ & \\
\hline \multicolumn{5}{|l|}{ TUG Test (seconds) } \\
\hline Baseline & 12.4 & 10.1 & 15.4 & 0.045 \\
\hline Time 2 & 14.8 & 11.0 & 19.8 & \\
\hline Time 3 & 14.6 & 10.5 & 18.7 & 0.013 \\
\hline Change & $18 \%$ & $4 \%$ & $21 \%$ & \\
\hline \multicolumn{5}{|l|}{ PADS (total points) } \\
\hline Baseline & 117.3 & 137.6 & 90.2 & 0.563 \\
\hline Time 2 & 120.8 & 129.3 & 109.6 & \\
\hline Time 3 & 168.6 & 140.0 & 197.1 & 0.636 \\
\hline Change & $44 \%$ & $2 \%$ & $119 \%$ & \\
\hline \multicolumn{5}{|c|}{ RBANS Delayed Memory Index } \\
\hline Baseline & 74.0 & 75.0 & 72.7 & 0.922 \\
\hline Time 2 & 81.9 & 87.3 & 74.7 & \\
\hline Time 3 & 76.3 & 74.0 & 79.3 & 0.828 \\
\hline Change & $3 \%$ & $-1 \%$ & $9 \%$ & \\
\hline
\end{tabular}

All outcome variable data are expressed as means. P-value was calculated using an unpaired t-test and represents the between PD and ABI group differences.

SPPB (4m walk, balance, repeated chair stands) - physical function

SPPB Gait Speed - 4 meter walk measured in seconds

SPPB Chair Stand - repeated chair stands measured in seconds

TUG Test -8 meter mobility test measured in seconds

PADS score - physical activity level

RBANS delayed memory index (list recall, list recognition, story recall, and figure recall) - recall and recognition 
Table 3: Gait Speed Time Changes Within Cohort, PD and ABI Groups and Between PD and ABI Groups

\begin{tabular}{|l|c|c|c|}
\hline Gait Speed (seconds) & Mean Change & Std Dev & P-value \\
\hline Within All & -1.57 & 1.19 & 0.384 \\
\hline Within PD & -0.85 & 0.76 & 0.100 \\
\hline Within ABI & -2.53 & 0.97 & $0.032 *$ \\
\hline Between PD \& ABI & & & 0.384 \\
\hline
\end{tabular}

*Significant at $\mathrm{p}<0.05$

SPPB Gait Speed $-4 \mathrm{~m}$ walk measured in seconds

Table 4: TUG Changes Within Cohort, PD and ABI Groups and Between PD and ABI Groups

\begin{tabular}{|l|c|c|c|}
\hline TUG (seconds) & Mean Change & Std Dev & P-value \\
\hline Within All & 2.21 & 1.91 & 0.190 \\
\hline Within PD & 1.10 & 1.01 & 0.876 \\
\hline Within ABI & 3.33 & 2.09 & $0.054^{*}$ \\
\hline Between PD \& ABI & & & 0.190 \\
\hline
\end{tabular}

*Significant at $\mathrm{p}=0.05$

TUG Test - 8m mobility test measured in seconds 
Table 5: Baseline, Time 2, Time 3 Data and Change for each Participant

\begin{tabular}{|c|c|c|c|c|}
\hline Outcome Measures & Baseline & Time 2 & Time 3 & Change \\
\hline \multicolumn{5}{|l|}{ SPPB Score } \\
\hline Participant 1 & 9 & 7 & 4 & $-56 \%$ \\
\hline Participant 2 & 10 & 10 & 9 & $-10 \%$ \\
\hline Participant 3 & 10 & 10 & 11 & $10 \%$ \\
\hline Participant 4 & 11 & 12 & 11 & $0 \%$ \\
\hline Participant 5 & 8 & 8 & 9 & $13 \%$ \\
\hline Participant 6 & 7 & 9 & 11 & $57 \%$ \\
\hline Participant 7 & 5 & 5 & 4 & $-20 \%$ \\
\hline \multicolumn{5}{|l|}{ Gait Speed } \\
\hline Participant 1 & 6.09 & 4.08 & 6.05 & $-1 \%$ \\
\hline Participant 2 & 4.3 & 2.87 & 3.14 & $-27 \%$ \\
\hline Participant 3 & 4.78 & 3.34 & 3.04 & $-36 \%$ \\
\hline Participant 4 & 4.16 & 4.22 & 3.72 & $-11 \%$ \\
\hline Participant 5 & 5.81 & 5.19 & 4.37 & $-25 \%$ \\
\hline Participant 6 & 7.31 & 5.83 & 4.48 & $-39 \%$ \\
\hline Participant 7 & 9.68 & 7.89 & 6.37 & $-34 \%$ \\
\hline \multicolumn{5}{|l|}{ SPPB Chair Stands } \\
\hline Participant 1 & 10.47 & N/A & N/A & \\
\hline Participant 2 & 14.31 & 14.93 & 18.19 & $27 \%$ \\
\hline Participant 3 & 16.16 & 12.09 & 12.27 & $-24 \%$ \\
\hline Participant 4 & 12.46 & 10.46 & 12 & $-4 \%$ \\
\hline Participant 5 & 13.5 & 10.16 & 11.16 & $-17 \%$ \\
\hline Participant 6 & 12.25 & 13.41 & 12.87 & $5 \%$ \\
\hline Participant 7 & N/A & 26.29 & N/A & \\
\hline \multicolumn{5}{|l|}{ TUG test } \\
\hline Participant 1 & 12.22 & 13.48 & N/A & \\
\hline Participant 2 & 8.16 & 9.71 & 9.93 & $22 \%$ \\
\hline Participant 3 & 10.79 & 9.91 & 10.72 & $-1 \%$ \\
\hline Participant 4 & 9.16 & 11.06 & 10.75 & $17 \%$ \\
\hline
\end{tabular}




\begin{tabular}{|c|c|c|c|c|}
\hline Participant 5 & 11.5 & 15.03 & 16.3 & $42 \%$ \\
\hline Participant 6 & 16.43 & 17.12 & 17.37 & $6 \%$ \\
\hline Participant 7 & 18.31 & 27.36 & 22.56 & $23 \%$ \\
\hline PADS Score & \multicolumn{5}{|l|}{} \\
\hline \hline Participant 1 & 46.5 & 22.8 & -21 & $-145 \%$ \\
\hline Participant 2 & 310.9 & 176.6 & 291.9 & $-6 \%$ \\
\hline Participant 3 & 86 & 161.7 & N/A & \\
\hline Participant 4 & 107.1 & 156 & 149.1 & $39 \%$ \\
\hline Participant 5 & 155.6 & 137.6 & 302.2 & $94 \%$ \\
\hline Participant 6 & 26.4 & 165.5 & 212.4 & $705 \%$ \\
\hline Participant 7 & 88.5 & 25.6 & 76.7 & $-13 \%$ \\
\hline RBANS Delayed Memory Index & & & \\
\hline \hline \multicolumn{7}{|c|}{ Participant 1 } & 40 & 60 & 44 & $10 \%$ \\
\hline Participant 2 & 102 & 112 & 106 & $4 \%$ \\
\hline Participant 3 & 56 & 75 & 52 & $-7 \%$ \\
\hline Participant 4 & 102 & 102 & 94 & $-8 \%$ \\
\hline Participant 5 & 94 & 97 & 97 & $3 \%$ \\
\hline Participant 6 & 44 & 44 & 44 & $0 \%$ \\
\hline Participant 7 & 80 & 83 & 97 & $21 \%$ \\
\hline
\end{tabular}

SPPB (4m walk, balance, repeated chair stands) - physical function SPPB Gait Speed - 4 meter walk measured in seconds SPPB Chair Stand - repeated chair stands measured in seconds TUG Test -8 meter mobility test measured in seconds PADS score - physical activity level RBANS delayed memory index (list recall, list recognition, story recall, and figure recall) - recall and recognition 


\section{APPENDICES}

\section{Appendix A: Review of the Literature}

\section{Introduction}

Traumatic brain injury (TBI) and stroke affect 1.7 million and 795,000 Americans each year respectively ${ }^{1,2}$. At the same time, approximately one million people in the United States are living with Parkinson's disease ${ }^{3}$. Parkinson's disease (PD), TBI and stroke disabilities include decreased ability to communicate, difficulty maintaining a healthy diet, and reduced levels of physical activity and physical function. However, limited longitudinal data exist on these behaviors beyond the acute phases of recovery and in the chronic phases of rehabilitation ${ }^{4}$.

The purpose of this literature review is to describe the epidemiology of PD, TBI and stroke and their association with physical function, specifically gait speed, in the chronic stages of the diseases. The report will also review current research that examined gait speed as a measure of physical performance and function in these populations.

\section{Parkinson's Disease}

Parkinson's disease is a chronic and progressive movement disorder that worsens over time and affects two percent of individuals age 60 years and older ${ }^{5}$. Older males have a higher risk of developing $\mathrm{PD}^{6}$. The prevalence and incidence increases with age and peaks after 80 years of age. The male to female ratio for disease is approximately $3: 2^{7}$. Family history has also been found to be a strong predictor ${ }^{5}$. Ethnicity is a risk factor with Hispanics having the highest risk followed by non- 
Hispanic whites, Asians and Blacks ${ }^{7}$. With the aging of the population, a 50 percent increase in adults with the disease is expected by $2030^{7}$.

The cause of PD is not completely understood and there is presently no cure ${ }^{3}$. The condition likely results from the attrition of dopamine producing neurons that regulate motor function, genetics or environmental exposures ${ }^{5}$. Loss of dopaminergic neurons within the substantia nigra pars compacta $(\mathrm{SNpc})$ has been noted to be the key pathological feature in $\mathrm{PD}^{7}$. There is a 9-13 percent loss of these neurons for every 10 years of life and 70-80 percent of these neurons are lost before the first symptoms appear $^{5}$. Lewy pathology is another characteristic of PD. Lewy bodies in surviving SNpc neurons appear to have causal roles in neuronal loss in PD. Neuroinflammation is another characteristic; however, the whether neuroinflammation promotes or protects from neurodegeneration has yet to be determined. Genetics also plays a role in PD factors and multiple genes have associated with PD based on mutations identified as causes of familial $\mathrm{PD}^{7}$.

Precipitating factors include a history of mild to moderate head injury, betablocker use and exposure to toxicants including the herbicide paraquat ${ }^{6,7}$. Factors associated with a decreased risk for developing the disease include physical activity, non-steroidal anti-inflammatory drug use, calcium channel blocker use, alcohol consumption and protective genetic factors. Smoking and coffee consumption have also been reported to be lower in adults who develop PD. Smoking may be reduced due to the decreased response to nicotine during early $\mathrm{PD}^{6,7}$.

Individuals with PD experience motor symptoms including resting tremors, rigidity, hypokinesia, bradykinesia and postural instability. Secondary symptoms 
include stooped posture; impaired coordination; decreased cognition, attention, executive function, memory; dementia; sleep disorders; sensory changes; speech problems; and difficulty swallowing ${ }^{3}$. Progression of PD is characterized by worsening of the motor symptoms. In the late stages of the disease, treatment resistant motor and non-motor characteristics including postural instability, freezing of gait, falls, dysphagia and speech dysfunction become prominent. Eighty percent of adults with the disease are reported to have freezing of gait and falls and 50 percent choking after 17 years of disease. Dementia is reported in 83 percent of adults after 20 years of disease duration ${ }^{7}$. Older age at the onset the disease has been associated with faster rates of motor progression and mortality. Early onset may increase the risk for dystonia ${ }^{6}$.

Clinical diagnosis of PD is based on the presence of parkinsonian motor features and absence of other diseases that cause Parkinsonism. Diagnostic tests for definitive diagnosis in the early stages of the disease do not exist. The presence of moderate to severe SNpc degeneration and Lewy pathology at the post mortem exam is the current gold standard for diagnosis ${ }^{7}$.

Therapies for PD treat the symptoms and not the underlying causes of PD. The goals of pharmacological treatments are to improve function and quality of life and should be started at diagnosis. Treatment for motor symptoms include dopamine replacement and dopamine agonists. The medications include levodopa, dopamine agonists, monoamine oxidase type B inhibitors and amantadine. Non-motor treatments are condition specific and are often have a limited response ${ }^{7}$. 
Deep brain stimulation is also effective in treating tremors and motor symptoms moderate to severe PD. This surgical treatment is implicated in cases where motor symptoms respond to levodopa but motor fluctuations and dyskinesia become disabling. The treatment can also improve non-motor fluctuations in sleep-related symptoms and behavioral abnormalities and is usually performed 10-13 years after diagnosis ${ }^{7}$.

Treatments including the introduction of dopamine agonist and dopamine replacement therapy are frequently based on change of functional status. Changes in functional status and disability are commonly assessed through surveys or physical functioning assessment ${ }^{8}$. Gait impairment is a common finding in individuals diagnosed with PD and is characterized by decreased gait speed, shortened steps, stooped posture and reduced arm swing 9,10 . It is a common focus of pharmacological, behavioral and surgical intervention and gait speed has been singled out as a measure due to its relevance to community independence and predictive value for important health outcomes and mortality ${ }^{10}$.

Haas et al. ${ }^{10}$ studied the minimal clinically important difference (MCID) for gait speed in adults in various stages of PD. Data for the study were collected on 324 individuals currently receiving pharmacological treatment for their PD symptoms. Sixty seven percent of the participants were male. The average age of the cohort was 68 with a standard deviation (SD) of 10 . The time since diagnosis averaged 8 years (SD 6). The methods used to measure gait speed included the $5.8 \times 0.9$ meter (m) GAITRite instrument walkway system. The participants performed four walking trials at a comfortable pace. The course started $1.5-\mathrm{m}$ before the walkway and ended $1.5-\mathrm{m}$ 
after the walkway to minimize acceleration and deceleration effects. None of the participants used assistive devices and in the event of a freezing episode additional walks were performed. Cross sectional analysis of the clinically important differences for gait speed was completed using disability (Schwab and England Activities of Daily Living Scale), disease stage (Modified Hoehn and Yahr Scale (H\&Y)) and severity (Unified Parkinson's Disease Rating Scale (UPDRS)) distribution and anchor based approaches. The distribution measures relied on the distribution of scores as in the minimal detectable change (MDC) and effect size and anchor approaches relied on responsiveness to independent measures. The magnitude of effect for the distribution approach was based on the Cohen effect size recommendations of 0.2 as small, 0.5 as moderate and 0.8 as large. The average gait speed was $0.98 \mathrm{~m} / \mathrm{s}$ with a range of $0.22-$ $1.73 \mathrm{~m} / \mathrm{s}(\mathrm{SD} 0.27 \mathrm{~m} / \mathrm{s})$. Using distribution based analysis, the MCID ranged from $0.05 \mathrm{~m} / \mathrm{s}$ to $0.22 \mathrm{~m} / \mathrm{s}$. Whereas, the MCID ranged from $0.02 \mathrm{~m} / \mathrm{s}$ to $0.15 \mathrm{~m} / \mathrm{s}$ through the use of anchor based metrics. A key limitation of the study was using only short, straight walking distance that is not reflective of community ambulation. The results of the study will serve as a tool for evaluating intervention effectiveness and benchmarking treatment effects for individuals with PD on medication ${ }^{10}$.

A study by Tanji et al. ${ }^{8}$ compared physical performance measures for their ability to discriminate between levels of disability and disease severity in PD. The cohort included 79 individuals age 65.5 (SD 10.6) years with PD. The participants were tested with seven physical performance measures including the Physical Performance Test (PPT), modified PPT (mPPT), SPPB, Performance Test of Activities of Daily Living (PADL), Berg Balance Scale (BBS), TUG test and Functional Reach (FR). 
Disability was assessed using the Older Americans Resource and Services and Disability Subscale (OARS) and severity was assessed using the UPDRS. The participants were divided into quartiles based on their OARS and UPDRS ratings. All seven measures discriminated across the quartiles of the total severity ratings (PPT, mPPT, BBS, TUG, FR: $\mathrm{p}<0.01$; SPPB, PADL: $\mathrm{p}<0.05)$ and four measures discriminated across the disability ratings (PPT, mPPT, BBS, TUG: $\mathrm{p}<0.05$ ). All of the measures were more strongly associated with severity than disability and declined as the participants moved to worsening stages of severity. The SPPB, BBS and TUG correlated significantly with both disability (SPPB $r=0.41-0.56, \mathrm{p}<0.05$; BBS $r=$ $0.55-0.60, \mathrm{p}<0.01 ;$ TUG $r=0.37-0.58, \mathrm{p}<0.05)$ and severity (SPPB $r=0.56-$ $0.59, \mathrm{p}<0.01 ; \mathrm{BBS} r=0.59-0.74, \mathrm{p}<0.01 ;$ TUG $r=0.52-0.67, \mathrm{p}<0.01)$ measures. The FR correlated significantly only with the severity $(r=0.45-0.69, \mathrm{p}<$ $0.05)$ measures. The results indicated that the performance measures were more sensitive to severity than disability. However, none of measures consistently discriminated between levels of PD severity or disability. The investigators concluded that assessment of interventions aimed at gait and balance are enhanced by assessing functional measures including the SPPB, TUG, BBS and FR. In addition, the SPPB, TUG and FR require only one to seven minutes to administer and are the best options for busy clinical practices where time and ease of administration are critical ${ }^{8}$.

Factors associated with exercise behaviors in individuals with PD were examined in a cross sectional study by Ellis et al ${ }^{11}$. There were 260 participants, age 40 years or greater, classified at $\mathrm{H} \& \mathrm{Y}$ stage 1-4 and receiving pharmacological treatments in the study. The Stages of Readiness to Exercise Questionnaire was used to designate 
participants as exercisers or non-exercisers. The Physical Activity Scale for the Elderly (PASE) along with an activity monitor were used to validate exercise status. The factors assessed included measures of body structure and function; activity; participation; and environmental and personal factors. The measures used to quantify factors associated with physical activity included the UPDRS (two groups - low severity score <40; high severity score $\geq 40$ ), Geriatric Depression Scale (GPS), 6 minute walk test, Parkinson's Disease Questionnaire-39 (participation), Self-Efficacy for Exercise (SEE) and personal and environmental factors. Sixty three percent of the participants were found to be exercisers. They had significantly lower UPDRS motor scores $(\mathrm{p}<0.02)$, less depression $(\mathrm{p}<0.00)$, less restrictions in participation $(\mathrm{p}<$ $0.001)$, higher self efficacy $(\mathrm{p}<0.001)$ and higher education $(\mathrm{p}<0.00)$ than the nonexercisers. Self efficacy $(\mathrm{p} \leq 0.05)$ and education level $(\mathrm{p} \leq 0.05)$ were more strongly associated with exercise behavior than disease severity, activity limitations or restrictions in participation. Limitations of the study included using the selfadministered PASE to validate exercise behavior. The results suggested self efficacy and the confidence to face barriers to exercise as a potential target for intervention ${ }^{11}$. Individuals with PD may have difficulty walking outside the home environment due to terrain characteristics, time constraints, walking distance and fluctuations in impairment. Gait speed is one aspect of community walking and was compared with demographic characteristics and clinical variables in a cross sectional study by Elbers et al. ${ }^{12}$. The aim of the study was to examine if comfortable gait speed was a valid measure to predict community walking in adults with PD on medication. Participants were excluded if they undergone deep brain stimulation or experienced cognitive 
impairment. The cohort consisted of 153 participants with a mean age of 67 years (SD 7.54) diagnosed with PD. The evaluations were in the participants' homes approximately one hour after taking medications. The Nottingham Extended Activities of Daily Index was used to identify community walkers. Seventy or 46 percent of the participants were classified as community walkers. Gait speed was measured with the 10-m walk test repeated three times. A minimum distance of 6-m was used to adapt to constraints in the participants' homes. The time was converted to $\mathrm{m} / \mathrm{s}$ and the mean gait speed was $0.84 \mathrm{~m} / \mathrm{s}$ (SD 0.20). The investigators established 0.88 seconds as a cut off value to discriminate between non-community and community walkers. A receiver operating characteristic curve was constructed to investigate the diagnostic accuracy of gait speed as a predictor for community walking and showed that a cut-off point of $0.88 \mathrm{~m} / \mathrm{s}$ correctly classified 70 percent of the participants as community walkers and 72 percent as non-community walkers. Multivariate regression analysis was also performed to evaluate the added value of demographic and clinical variables in predicting community walking. Fear of falling was found to have an added value in predicting community walking. Study limitations included conducting the gait speed test in the participants' homes and modifying the distance from 6-10 meters. The results indicated that timed walking tests are valid measures of community walking and that individuals who experience less fear of falling are more likely to be community walkers ${ }^{12}$.

In summary, the articles reviewed provided study results concerning physical performance measures, clinically important differences in gait speed, community walking values and barriers to adopting physical activity among persons with PD. 
Interventions assessing gait speed, where ease of administration and time are factors, will be enhanced by using the SPPB, TUG and $\mathrm{FR}^{8}$. The clinically important difference in gait speed ranged from $0.05 \mathrm{~m} / \mathrm{s}$ to $0.22 \mathrm{~m} / \mathrm{s}$ by distribution based analysis and $0.02 \mathrm{~m} / \mathrm{s}$ to $0.18 \mathrm{~m} / \mathrm{s}$ by anchor based analysis ${ }^{10}$. Timed gait speeds tests were reported to be valid measures to predict community walking and the recommended cut-off value is $0.88 \mathrm{~m} / \mathrm{s}^{12}$. Finally, self-efficacy and fear of falling are behaviors that contribute to physical activity in individuals with $\mathrm{PD}^{11,12}$. The data in each of the studies was from a cross sectional cohort rather than a longitudinal evaluation.

\section{Acquired Brain Injury - Stroke}

Acquired brain injury (ABI) is structural damage to the head after birth and includes cerebrovascular accidents and $\mathrm{TBI}^{13}$. A cerebrovascular accident or stroke occurs when a vessel in the brain is occluded or ruptures and is the fifth leading cause of death and a leading cause of preventable disability in the United States (U.S.) ${ }^{14,15}$. An occluded vessel in brain results in an ischemic stroke whereas a blood vessel rupturing results in a hemorrhagic stroke. Ischemic strokes account for 87 percent of all strokes, and there is also a condition resulting from a temporary occlusion termed transient ischemic attack (TIA) that produces stroke like symptoms but no lasting damage $^{14}$.

An estimated 6.8 million Americans over the age of 20 have experienced a stroke. The overall prevalence is 2.8 percent for this population ${ }^{2}$. Over the past 10 years, the actual number of stroke deaths declined by 21.2 percent, but approximately 795,000 
individuals continue to experience an ischemic or hemorrhagic stroke annually. The decline in stroke mortality is attributed to the improvement in population health and concurrent with the interventions to control cardiovascular risk factors. The hypertension control efforts appear to have the most influence along with control of diabetes mellitus and hyperlipidemia, and smoking cessation ${ }^{16}$.

The disease is seen primarily in adults over age 65, African Americans and people living in the southeastern United States and is a major cause of long term disability $^{2,13}$. African-Americans have nearly twice the risk for a first stroke than Caucasians and a much higher death rate from stroke. This is attributed to the higher risk of higher risk of high blood pressure, diabetes and obesity found in African Americans. Females have more strokes than men with approximately 60 percent of the stroke deaths occurring in women. Hormonal therapy used to prevent pregnancies and increase estrogen levels in postmenopausal women, pregnancy, a history of preeclampsia/eclampsia or gestational diabetes, and smoking increase the risks for women. Heredity also plays a key role with stroke risk increasing if grandparents, parents or siblings have experienced a stroke. Strokes may also be symptoms of inherited genetic disorders including Cerebral Autosomal Dominate Arteriopathy with Sub-Cortical Infarct and Leukoencephalopathy (CADASIL). Finally, individuals who have experienced a stroke are at a higher risk for additional strokes ${ }^{14}$.

The primary risk factors for stroke include hypertension, diabetes mellitus, hyperlipidemia, atrial fibrillation, smoking, heredity and physical inactivity ${ }^{2,14}$. The American Stroke Association has identified hypertension as the leading cause of stroke and also described the following risk factors. 
-Diabetes mellitus is an independent risk factor and is also associated with high blood pressure, hyperlipidemia and obesity.

- Hyperlipidemia can lead to atherosclerosis or the build-up of plaque in the arteries resulting in narrowing of arterial walls and the risk for plaques breaking open, bleeding and forming emboli.

- Atrial fibrillation can let blood pool and coagulate in the atrium and result in an embolus raising the risk for a stroke.

-The nicotine and carbon monoxide associated with smoking cigarette damages the cardiovascular system and leads to dyslipidemia, hypertension, damaged endothelial cells, clotting of platelets and a decreased tolerance for exercise.

- Physical inactivity can increase the risk for hypertension, diabetes, heart disease and stroke ${ }^{14}$.

Stroke prevention involves managing the enabling factors listed above.

Pharmacological therapies may also be required to control and manage hypertension, diabetes mellitus, hyperlipidemia and atrial fibrillation in high risk individuals. Additionally, medical procedures including carotid endarterectomy may be required to remove plaque from effected arteries ${ }^{14}$.

Immediate treatment may minimize the effects of ischemic strokes. The gold standard for treatment is the FDA approved tissue plasminogen activator (tPA). This thrombolytic treatment is delivered intravenously and works by dissolving the clot to improve blood flow in the affected area of the brain. The individual's chances for recovery are improved if the medication is delivered within three hours and up to 4.5 hours for certain patients. Endovascular procedures and surgical treatments are used 
to treat hemorrhagic strokes. Endovascular procedures involve guiding a catheter from a major artery in the arm or leg and inserting a device to prevent rupture of an aneurysm or arteriovenous malformation (AVM). Surgical treatment may be required to stop hemorrhage caused by ruptured aneurysm or $\mathrm{AVM}^{14}$.

The acute symptoms of stroke include face drooping or numbness, arm hemiparesis, and speech difficulty. Other sudden symptoms include hemiparesis or numbness of the leg, arm or face; confusion or trouble understanding; visual disturbances in one or both eyes; trouble walking, dizziness, loss of balance or coordination; and a severe headache with no known cause. Diagnosis is confirmed through physical and neurological assessment and a computerized axial tomography (CT) scan or magnetic resonance imaging (MRI) of the brain ${ }^{14}$.

Six months after stroke, nearly 50 percent of stroke survivors continue to experience hemiparesis and cognitive linguistic deficits and thirty percent are unable to walk without assistance ${ }^{2}$. Approximately, 12 to 43 percent of stroke survivors experience further deterioration in mobility including walking speed and falls one to three years after diagnosis. As a result, independent ambulation in the home or community may be compromised. Factors affecting mobility are responsive to modifications in physical activity; however, are scarcely described in the literature ${ }^{17}$.

A cross-sectional study by Vahlberg et al. ${ }^{17}$ examined the post stroke population to assess mobility and physical activity and their relationship to physical, psychological and demographic factors. The sample included 195 community-living individuals age 65-85 years who had experienced a stroke in the last one to three years. Mobility was measured using the SPPB and physical activity was assessed 
using the self-reported PASE. The performance based measures also included the Berg Balance Scale and 10-m walking test. The mean SPPB score was 8.7 with a standard deviation of 2.9. The mean comfortable gait speed for the $10-\mathrm{m}$ walk test was to found to be $1.10 \mathrm{~m} / \mathrm{s}$ for the cohort and $1.16 \mathrm{~m} / \mathrm{s}$ and $0.94 \mathrm{~m} / \mathrm{s}$ for men and women respectively. The results of both performance measures were found to be below the results for a healthy population sample. The findings of the study reported that performance based mobility was independently related to physical activity level, fall related self efficacy and health-related quality of life. Likewise, physical activity level was related to mobility, fall related self efficacy and health-related quality of life. The investigators recommended future studies to evaluate the effect of actions to improve mobility and fall-related self efficacy on physical activity levels in the poststroke population $^{17}$.

Stookey et al. ${ }^{18}$ further analyzed the use the SPPB as a predictor of functional capacity after stroke. Functional capacity was defined as those performance measures that more closely mimic the endurance and distance requirements of community ambulation. Forty three participants between the age of 43 and 87 were evaluated. Each participant had completed conventional inpatient and outpatient physical therapy and was six months post ischemic stroke or 12 months post hemorrhagic stroke. The measures included the SPPB total score and component results ( 8 foot walk, standing balance, chair stand); 6-minute walk; and VO2 Peak treadmill test (aerobic capacity). Forty participants had a total SPPB scores of less than 10; an accepted threshold for functional impairment. Thirty two participants scored one or zero on the chair stand test. There was a significant correlation between the SPPB and the 6-minute walk $(r=$ 
$0.76, \mathrm{P}<.001)$ and peak treadmill test $(r=0.52, \mathrm{p}<.001)$. The 6-minute walk relationship indicated that long distance walking capacity is captured by the SPPB. The participants with higher SPPB scores were also found to walk a greater distance the 6-m walk test. The study results indicated that the SPPB may be reflective of endurance based, longer distance measures in chronic stroke patients ${ }^{18}$ although gait tests that involve changes of direction may be more reflection of mobility and community ambulation requirements.

The relationship between gait speed and community ambulation has been reported in post-stroke individuals. Perry and al. ${ }^{19}$ tested 147 stroke patients that were at least three months post stroke. The investigators assessed functional walking ability through a walking ability questionnaire along with testing gait speed (10-m walk test), muscle strength, proprioception. Gait speed was found to be the most efficient predictor of household or community ambulation. Participants with an average speed of $0.4 \mathrm{~m} / \mathrm{s}$ were predicted to have the ability for community ambulation with the highest category of community walking being $0.8 \mathrm{~m} / \mathrm{s}^{19}$. Schmid et al. ${ }^{20}$ further stratified gait speed into three classifications: household ambulation $(<0.4 \mathrm{~m} / \mathrm{s})$, limited community ambulation $(0.4$ to $0.8 \mathrm{~m} / \mathrm{s})$ and full community ambulation $(>0.8$ $\mathrm{m} / \mathrm{s}$ ). They studied 64 patients that were over 50 years old and 3-28 days post-stroke to determine whether improvements in classification were related to clinically meaningful changes in function and quality of life. The assessed gait speed using the 10-m walk test and function and quality of life using the Stroke Impact Scale (SIS). Twelve of 19 household ambulators transitioned to limited community ambulation whereas 17 of 45 limited community ambulators became full community ambulators. 
The function and quality of life SIS scores were significantly higher for the household $(\mathrm{p}=0.0299)$ and limited community $(\mathrm{p}=0.0085)$ participants that advanced in classification. The results supported the conclusion that a gain in gait speed that results in a transition to a higher classification results in an improved function and quality of life ${ }^{20}$.

A study of community ambulation conducted by van de Port et al. ${ }^{21}$, also examined the association between gait speed and community ambulation and added the effect of other confounding factors including age, living alone, history of falls, assistive walking devices, executive function, depression, fatigue, motor function, balance and walking endurance. Community ambulation was characterized by four categories: inability to walk outside; ability to walk to the car or mailbox without assistance; ability to walk in the immediate outdoor environment without assistance; and ability to walk to stores, neighbors or activities without assistance. The sample included 72 post stroke individuals with a mean age of 59 years. The data were collected three years after the individual experienced the stroke. Gait speed was measured in the participant's home with the 5-m walking test. Seventy four percent of the participants were identified as community walkers and 26 percent as non- or limited community walkers. The average gait speed was $0.74 \mathrm{~m} / \mathrm{s}$ (SD 0.30). The optimal cut-off point for community ambulation of $0.66 \mathrm{~m} / \mathrm{s}$ was determined using receiver operation characteristic curve. Gait speed was found to be significantly related to community ambulation and remained the significant determinant after the confounders were added to the analysis. However, several factors were noted to contribute to community walking ability including balance, motor function, endurance 
and use of assistive walking devices. Also, mobility is thought to be time-dependent by the investigators and may decline over time ${ }^{21}$.

Schmid et al. ${ }^{22}$ studied individuals with chronic stroke to identify the mobility impairment most associated with the individual's activity in performance of tasks or actions, and participation in life situations, i.e. returning to work. The cross-sectional study sample consisted of 77 participants with an average age of 64 who were six months post stroke. The outcome measures included gait speed (10-m walk) and walking capacity (6-minute walk); balance (Berg Balance Scale); balance self-efficacy (Activities-specific Balance Confidence); and falls self-efficacy (Modified Fall Self Efficacy Scale). The gait speed for the $10-\mathrm{m}$ walk was $1.33 \mathrm{~m} / \mathrm{s}$ with a standard deviation of 1.33 , relatively high for individuals with chronic stroke. The study results showed a stronger correlation between balance self efficacy and post-stroke activity and participation (activity, $r=-.544, \mathrm{p}<.001$; participation, $r=-.459, \mathrm{p}<.001$; total activity and participation, $r=-.548, \mathrm{p}<.001)$ than with the physical performance measures of balance, gait speed and walking capacity. There was also strong relationship between gait speed and activity $(r=-.309, \mathrm{p}=.006)$; however, gait speed only weakly correlated with participation or total $\operatorname{scores}^{22}$.

A longitudinal study examining clinical determinants of deterioration in mobility from one to three years post-stroke was also found in the literature. At one year poststroke, 264 participants aged 57 years (SD 11) were assessed. The sample decreased to 205 participants at three years post-stroke with attrition attributed to withdrawals from the study, death and individuals lost to follow up due to relocation. The independent variables included patient and stroke characteristics, physical factors 
(Motricity Index), cognitive factors (mini mental state examination) and social factors (Social Support List). The outcome variable, mobility, was assessed using the Rivermead Mobility Index (RMI) that consists of 14 questions and one observation. The RMI index score ranged from zero to 15 and a drop of $\geq$ two points was considered deterioration in mobility. Mobility decline was found in 21 percent of the participants between one and three years $(\mathrm{p}<0.05)$. Multivariate analysis showed that level of activity, cognitive problems, fatigue and depression were statistically significant predictors of mobility decline (Hosmer-Lemeshow test $p>0.05$ ). The results indicated that mobility decline is more strongly associated with psychological and cognitive factors rather that physical factors. The investigators suggested that early recognition and treatment of these risk factors may assist in preventing deterioration of mobility status ${ }^{23}$.

Each of the cross sectional studies used gait speed as a measure of physical function in the post stroke population. Gait speed was reported to be the most efficient predictor of household and community ambulation, a significant determinant of community ambulation, and a powerful indicator of function and prognosis poststroke $^{19,20,21}$. An increase in gait speed was also reported to result in better function and quality of life ${ }^{20}$. Gait speed was stratified into three community ambulation classifications: household ambulation $(<0.4 \mathrm{~m} / \mathrm{s})$, limited community ambulation $(0.4$ to $0.8 \mathrm{~m} / \mathrm{s})$ and full community ambulation $(>0.8 \mathrm{~m} / \mathrm{s})^{19,20}$. The optimal cut-off point for community ambulation was later suggested to be $0.66 \mathrm{~m} / \mathrm{s}^{21}$. The SPPB was found to be reflective of endurance based, longer distance measures in chronic stroke patients ${ }^{18}$ and related to physical activity level, fall related self efficacy and health- 
related quality of life ${ }^{17}$. Balance self efficacy was a behavior also found to be strongly correlated to post-stroke activity and participation ${ }^{17,22}$. Finally, a longitudinal study indicated that mobility decline is more strongly related with the presence of cognitive problems, depression and fatigue rather than physical factors ${ }^{23}$.

\section{Acquired Brain Injury - Traumatic Brain Injury}

Traumatic brain injury is caused by an external blow or jolt to the head or an object penetrating the skull that disrupts the normal function of the brain. A mild TBI may cause a temporary dysfunction of the brain cells resulting in a brief loss of consciousness or change in mental status. More severe injuries result in an extended

loss of consciousness, memory loss or death ${ }^{24,25}$. The conditions caused by brain injury can lead to physical, cognitive, and psychosocial issues and may cause associated conditions including seizures, impaired reasoning, apraxia and aphasia ${ }^{13}$. These individuals may also experience secondary sequelae including pain, depression, fatigue, sedentary lifestyle and obesity ${ }^{13}$. An estimated 5.3 million Americans or two percent of the population are living with a TBI related disability ${ }^{25}$.

Traumatic brain injury occurs most often within the age groups of 0-4 years, 1519 years, and over 65 years of age. Males are more likely to sustain a TBI in each of the age groups. Falls are the leading cause of TBI and motor vehicle accidents are the leading cause of TBI deaths ${ }^{1}$. Other leading causes of TBI include being struck by or against events, assaults, and sports and recreation activities. Blasts are the leading cause of TBI for military personnel assigned to war zones. Concussions and TBI resulting from sports and recreation activities are severely underestimated. In a 2006 
overview article, Langlois et al. ${ }^{26}$ estimated that 1.6 million to 3.8 million sports related TBIs occur each year. Their approximation includes those TBIs where no medical care is sought and may be low since major injuries go unrecognized ${ }^{26}$.

Long term treatment includes inpatient and outpatient rehabilitation to improve the individual's ability to perform activities of daily living ${ }^{24}$. Eighty-three percent of the individuals who suffer moderate to severe TBI will continue to demonstrate deficits in balance and gait after returning home impacting their activities of daily living and independence ${ }^{27}$.

A study done by Peters et al. ${ }^{27}$ assessed the impact of intensive mobility training on balance, mobility and gait speed in individuals with chronic TBI. Ten individuals aged 23.5 to 46 who were greater than three months post TBI participated in the study. The training was held five days per week for four weeks. Each session lasted 150 minutes and involved task specific training equally divided among balance, gait training, and strength and coordination. Minimal detectable changes along with outcome measures including a 10-m walk test (gait speed) and TUG test (mobility) were assessed. The MDC values for individuals with chronic stroke were substituted for comparison because MDC is sparsely studied for the TBI population. Participants demonstrated a significant change in walking speed and mobility at the 10 session interim, 20 session post-test and 3 month follow up evaluations. At the interim, posttest and follow-up evaluations, participants also exceeded the MDC for the walking speed test by 70,80 , and 60 percent respectively. There were smaller gains with the TUG test with 50 percent exceeding the MDC for the TUG test at post-test and 20 percent exceeding at follow-up. Overall, the participants demonstrated improvements 
in walking speed, mobility and balance post-intervention. The gait speed and mobility gains were also maintained at three months; however, no further evaluations were performed $^{27}$.

Several studies have suggested that postural instability contributes to slow gait speed in TBI patients ${ }^{28}$. However, a study by Williams et al. ${ }^{29}$ found that postural stability did not decrease with increasing gait speed and attributed reduced gait speed to biomechanical deficiencies. In the study, individuals with TBI were assessed using three dimensional gait analysis at self-selected $(n=55)$ and fast walking $(n=36)$ speeds over a 12 meter walkway and compared to 10 healthy control (HC) individuals that were speed matched to the mean TBI speeds. When compared to the HCs, the individuals with TBI were found to walk with similar cadence (self-selected speed TBI 99.72 (14.61) step/min, HC 97.14 (3.27); fast speed - TBI 122.28 (15.61) step/min, HC - $116.46(5.68)$ ) and step length (self-selected TBI - 0.61m (0.15) $0.64 \mathrm{~m}(0.12), \mathrm{HC}-0.64 \mathrm{~m}(0.03)$; fast speed TBI - 0.79m $(0.13)-0.82(0.11), \mathrm{HC}-$ 0.80m (0.03)); however, their ankle power at push off was reduced (self-selected speed - TBI 1.30 (0.72) W/kg, HC 1.75 (0.36); fast speed - TBI $1.91(0.86) \mathrm{W} / \mathrm{kg}, \mathrm{HC}$ - $2.98(0.32)$ ) and hip power in early stance (self-selected speed - TBI $1.24(0.72)$ W/kg, HC 0.58 (0.12); fast speed - TBI $2.81(1.73) \mathrm{W} / \mathrm{kg}, \mathrm{HC}-1.14(0.18))$ and preswing (self-selected speed - TBI $0.92(0.46) \mathrm{W} / \mathrm{kg}, \mathrm{HC} 0.53(0.12)$; fast speed TBI $1.55(0.83) \mathrm{W} / \mathrm{kg}, \mathrm{HC}-1.03(0.27))$ was increased. They were also found to have a significantly $(\mathrm{p}<0.001)$ increased width of the base of support (self-selected TBI - 0.24m (0.05), HC - 0.19m (0.02); fast speed TBI - 0.23m (0.05), HC - 0.19m (0.02)) and postural instability (self-selected TBI - 89.06mm (31.52), HC - 53.40mm 
(7.06); fast speed TBI $-76.27 \mathrm{~mm}$ (36.49), HC - 44.97mm (9.86)). The differences between the groups remained constant at the fast speed and postural stability was unchanged with increased gait speed; however, the gait tests were performed as straight-line walking and no changes in direction were performed ${ }^{29}$.

Driver et al. ${ }^{30}$ studied barriers to physical activity in individuals with traumatic brain injury. A convenience sample was used for the analysis and consisted of 28 participants aged 18 to 61 without significant cognitive impairment and enrolled in a comprehensive outpatient program. A 16 item questionnaire was used to measure demographics, physical activity participation, barriers to physical activity, perceived importance of physical activity and stage of exercise change. Additional questionnaires included the Behavioral Risk Factor Surveillance System (BRFSS), Barriers to Physical Activity Scale for People with Physical Disabilities (B-PADS) and Stages of Exercise Behavior Change. The participants reported zero to nine barriers per individual with the female participants reporting more barriers than the male participants. There were also differences in the barriers faced based on ethnicity and race. The most frequently reported behaviors for the cohort included environmental/facility and personal barriers. Lack of transportation and an accessible facility were the most frequently reported environmental/facility barriers. Insufficient endurance, feeling self-conscious in a fitness center and lack of time topped the personal barrier list along with the participants' disability preventing physical activity. The investigators also noted that the participants reported facing fewer barriers than reported in the literature for individuals with stroke. The participants may have 
perceived fewer barriers since they were only 57-90 days post injury and still involved in a comprehensive outpatient program ${ }^{30}$.

In summary, gait speed was also used to assess physical function in individuals with TBI. Postural stability was found to be stable with increasing gait speed and reduced gait speed was attributed to biomechanical deficiencies ${ }^{29}$. Intensive mobility training (IMT) was found to improve balance, mobility and gait speed in individuals with chronic TBI. The gait speed and mobility gains were also maintained at three months. The MDC values for individuals with chronic stroke were substituted for comparison because MDC is sparsely studied for the TBI population ${ }^{27}$. Finally, the barriers to physical activity most frequently reported by individuals with chronic TBI include lack of transportation, lack of an accessible facility, insufficient endurance, feeling self-conscious in a fitness center, lack of time along with the participants' disability preventing physical activity ${ }^{30}$. Each of the studies used a cross sectional design with exception of the study by Peters et al. Peters et al. ${ }^{27}$ used an experimental design with a pre-test, interim test (10 sessions), post-test (20 session) and a three month follow up evaluation ${ }^{27}$.

\section{Conclusions}

Individuals with chronic PD, TBI and stroke face declines in balance, coordination, strength, mobility and overall quality of life. Gait speed, coined the sixth vital sign, has been suggested to correlate with functional ability and balance confidence and aids in determining rehabilitation potential and fall risk. Additionally, 
gait speed progression has been linked to improvement in quality of life and is critical to maintaining community ambulation or independent mobility outside the home.

There is limited information in the literature about longitudinal changes in gait speed in individuals who are in the chronic stages of Parkinson's disease, stroke and traumatic brain injury. There is even less information that jointly examines gait speed in PD, stroke and TBI. The majority of studies reviewed measured gait speed using cross sectional analysis. Research has yet to examine the long term status of physical function and gait speed across the three chronic conditions.

\section{Resources Cited}

${ }^{1}$ Faul M., Xu L., Wald M. M., Coronado. V. G. (2010). Traumatic brain injury in the United States: emergency department visits, hospitalizations, and deaths. Centers for Disease Control and Prevention, National Center for Injury Prevention and Control.

${ }^{2}$ Go, A. S., Mozaffarian, D., Roger, V. L., Benjamin, E. J., Berry, J. D., Blaha, M. J., ... Turner, M. B. (2014). Heart Disease and Stroke Statistics - 2014 Update: A report from the American Heart Association. Circulation (129), e28-292.

${ }^{3}$ Parkinson's Disease Foundation (PDF). (2014) Understanding Parkinson's. http://www.pdf.org/. Accessed April 21, 2014.

${ }^{4}$ Mahler, L.A. (2013). Longitudinal Study of Communication, Nutrition and Physical Activity. (Unpublished Research Project Proposal). University of Rhode Island, Kingston, RI.

${ }^{5}$ Sweeney, P. Parkinson's Disease. (2013); http://www.clevelandclinicmeded.com/medicalpubs/diseasemanagement/neurology/pa rkinsons-disease/. Accessed June 6, 2015.

${ }^{6}$ Puschmann, A., Brighina, L., Markopoulou, K., Aasly, J., Chung, S. J., Frigerio, R., ... Maraganore, D. M. (2015). Clinically meaningful parameters of progression and long-term outcome of Parkinson disease: An international consensus statement. Parkinsonism \& Related Disorders, 1-8.

${ }^{7}$ Kalia, L. V, \& Lang, A. E. (2015). Parkinson's disease. The Lancet, 6736(14), 1-17. 
${ }^{8}$ Tanji, H., Gruber-Baldini, A. L., Anderson, K. E., Pretzer-Aboff, I., Reich, S. G., Fishman, P. S., ... Shulman, L. M. (2008). A comparative study of physical performance measures in Parkinson's disease. Movement Disorders : Official Journal of the Movement Disorder Society, 23(13), 1897-1905.

${ }^{9}$ Speciali, D. S., Oliveira, E. M., Cardoso, J. R., Correa, J. C. F., Baker, R., \& Lucareli, P. R. G. (2014). Gait profile score and movement analysis profile in patients with Parkinson's disease during concurrent cognitive load. Brazilian Journal of Physical Therapy, 18(4), 315-322.

${ }^{10}$ Hass, C. J., Bishop, M., Moscovich, M., Stegemöller, E. L., Skinner, J., Malaty, I. A, ... Okun, M. S. (2014). Defining the clinically meaningful change in gait speed in Parkinson's disease. Journal of Neurologic Physical Therapy, 38(4), 233-238.

${ }^{11}$ Ellis, T., Cavanaugh, J. T., Earhart, G. M., Ford, M. P., Forman, K. B., Fredman, L., Boudreau, J. K., Dibble, L. E. (2011). Factors Associated With Exercise Behavior in People with Parkinson Disease. Physical Therapy, 91(12), 1838-1848.

${ }^{12}$ Elbers, R. G., Van Wegen, E. E. H., Verhoef, J., \& Kwakkel, G. (2013). Is gait speed a valid measure to predict community ambulation in patients with Parkinson's disease? Journal of Rehabilitation Medicine, 45(4), 370-375.

${ }^{13}$ Driver, S., Irwin, K., Woolsey, A., \& Pawlowski, J. (2012b). Creating an effective physical activity-based health promotion programme for adults with a brain injury. Brain Injury, 26(12), 1482-1492.

${ }^{14}$ American Stroke Association. About Stroke. http://www.strokeassociation.org/ STROKEORG. Accessed June 7, 2015.

${ }^{15}$ Center for Disease Control and Prevention. Stroke. 2015; http://www.cdc.gov/stroke/. Accessed June 7, 2015.

${ }^{16}$ Mozaffarian, D., Benjamin, E. J., Go, A. S., Arnett, D. K., Blaha, M. J., Cushman, M., ... Turner, M. B. (2015). Executive Summary: Heart Disease and Stroke Statistics--2015 Update: A Report From the American Heart Association. Circulation, 131(4), 434-441.

${ }^{17}$ Vahlberg, B., Cederholm, T., Lindmark, B., Zetterberg, L., \& Hellström, K. (2013). Factors related to performance-based mobility and self-reported physical activity in individuals 1-3 years after stroke: A cross-sectional cohort study. Journal of Stroke and Cerebrovascular Diseases, 22(8), e426-34.

${ }^{18}$ Stookey, A. D., Katzel, L. I., Steinbrenner, G., Shaughnessy, M., \& Ivey, F. M. (2014). The short physical performance battery as a predictor of functional capacity after stroke. Journal of Stroke and Cerebrovascular Diseases, 23(1), 130-135. 
${ }^{19}$ Perry, J., Garrett, M., Gronley, J. K., \& Mulroy, S. J. (1995). Classification of walking handicap in the stroke population. Stroke; a Journal of Cerebral Circulation, 26(6), 982-989.

${ }^{20}$ Schmid, A., Duncan, P. W., Studenski, S., Lai, S. M., Richards, L., Perera, S., \& $\mathrm{Wu}$, S. S. (2007). Improvements in speed-based gait classifications are meaningful. Stroke, 38(7), 2096-2100.

${ }^{21}$ Van de Port, I. G., Kwakkel, G., \& Lindeman, E. (2008). Community ambulation in patients with chronic stroke: How is it related to gait speed? Journal of Rehabilitation Medicine, 40(1), 23-27.

${ }^{22}$ Schmid, A. A., Van Puymbroeck, M., Altenburger, P. A., Dierks, T. A., Miller, K. K., Damush, T. M., \& Williams, L. S. (2012). Balance and balance self-efficacy are associated with activity and participation after stroke: A cross-sectional study in people with chronic stroke. Archives of Physical Medicine and Rehabilitation, 93(6), 1101-1107.

${ }^{23}$ Van de Port, I. G. L., Kwakkel, G., Van Wijk, I., \& Lindeman, E. (2006).

Susceptibility to deterioration of mobility long-term after stroke: A prospective cohort study. Stroke, 37(1), 167-171.

${ }^{24}$ Mayo Clinic. (2012). Traumatic Brain Injury. http://www.mayoclinic.com/health/traumatic-brain-injury/DS00552. Accessed April 22, 2014.

${ }^{25}$ Center for Disease Control and Prevention. Traumatic Brain Injury. 2014; http://www.cdc.gov/traumaticbraininjury/. Accessed October 18, 2014.

${ }^{26}$ Langlois, J. A, Rutland-Brown, W., \& Wald, M. M. (2006). The epidemiology and impact of traumatic brain injury: a brief overview. The Journal of Head Trauma Rehabilitation, 21(5), 375-378.

${ }^{27}$ Peters, D. M., Jain, S., Liuzzo, D. M., Middleton, A., Greene, J., Blanck, E., ... Fritz, S. L. (2014). Individuals with chronic traumatic brain injury improve walking speed and mobility with intensive mobility training. Archives of Physical Medicine and Rehabilitation, 95(8), 1454-1460.

${ }^{28}$ Williams, G., Schache, A. G., \& Morris, M. E. (2013). Self-Selected Walking Speed Predicts Ability to Run Following Traumatic Brain Injury. Journal of Head Trauma Rehabilitation, 28(5), 379-385

${ }^{29}$ Williams, G., Morris, M. E., Schache, A., \& McCrory, P. R. (2010). People preferentially increase hip joint power generation to walk faster following traumatic brain injury. Neurorehabilitation and Neural Repair, 24(6), 550-558. 
${ }^{30}$ Driver, S., Ede, A., Dodd, Z., Stevens, L., \& Warren, A. M. (2012a). What barriers to physical activity do individuals with a recent brain injury face? Disability and Health Journal, 5(2), 117-125. 


\section{Appendix B: Extended Methodology}

An individual's ability to complete functional tasks can be predicted by examining physical performance. Objective tests that evaluate performance include the SPPB, gait speed and TUG test. The PADS provides a reliable and valid measure of physical activity for persons with disabilities. Cognition has also been associated with physical function and can be evaluated using the RBANS.

The SPPB was studied by Guralnik et al. ${ }^{1}$ and found to characterize older persons across a wide variety of functional status and predict mortality and nursing home admissions. The cohort for the study was part of the Established Populations for Epidemiologic Studies of the Elderly (EPESE) and consisted of 5,000 adults aged 71 or older in three communities. The measures included using three activities to assess the participant's lower extremity functioning: standing balance, 8 foot gait speed and repeated chair stands. The score range for each subtest was zero to four points with a maximum cumulative score of 12 points. Self-reported physical functioning included evaluating activities of daily living that required lower extremity function. The results of the study revealed that performance on each of the tests were strongly associated with self-reported disability and predictive of mortality and nursing home admissions ${ }^{1}$. Lower extremity function is thought to be predictive of disability because it reflects the effects of chronic disease, comorbidities, and physiological decline that are yet to cause obvious disability. A subsequent study by Guralnik et al. ${ }^{2}$ reported that participants with performance scores of less than 10 are more likely to have a disability in activities of daily living or a mobility related disability ${ }^{2}$. 
Kwon et al. ${ }^{3}$ analyzed data from the Lifestyle Interventions and Independence for Elders Pilot Study (LIFE-P) to determine the magnitude of meaningful change in the SPPB, 4-m gait speed and 400-m walk test. The participants were 424 sedentary adults aged $70-80$ who scored less than 10 on the SPPB and were able to complete a 400-m walk test in 15 minutes or less. The individuals were also participating in a structured physical activity intervention of the LIFE-P study. Participants who reported no difficulty or could not perform the activities were excluded from the study. The investigators applied anchored and distribution based methods for selfreported mobility to estimate minimal and substantial change in the performances measures over one year. Self-reported mobility status was gathered using a Disability Questionnaire and provided the anchor measures. The distribution based analysis used the effect size method and standard error of the measurement. The study reported the best estimates for a minimally meaningful change for the SPPB total score to be 0.3 to 0.8 points, 0.03 to $0.05 \mathrm{~m} / \mathrm{s}$ for the $4-\mathrm{m}$ gait speed, and 20 to 30 seconds for the $400-\mathrm{m}$ walk test. A range of 0.4 to 1.5 points for the SPPB, 0.08 for the $4-\mathrm{m}$ gait speed, and 50 to 60 seconds for the $400-\mathrm{m}$ walk test were reported as substantial change. The longitudinal format of the study was reported as a strength along with the LIFE-P study's intervention increasing the participants' potential to improve performance. The study limitations included the self-reported anchor measures and missing data at the 12-month evaluation. The study concluded that clinically important changes in performance measures were consistent using several analytical techniques and the changes appear to be attainable in clinical trials of exercise ${ }^{3}$. 
Gait speed alone has been suggested to correlate with functional ability and balance confidence and aids in determining rehabilitation potential and fall risk ${ }^{4}$. Additionally, gait speed progression has been linked to improvement in quality of life, 5. Coined the sixth vital sign, gait speed can provide a functional perspective to health status similar to temperature, pulse, respirations, blood pressure and pain ${ }^{4}$. Gait speed has also been identified as an important concern when determining the ability to ambulate outside of the home (or ambulate in the community) and distinguishing between limited and full community ambulation. Examples of gait speed recommendations in the community include the requirement to safely cross intersections and crosswalks. Andrews et al. ${ }^{6}$ studied these requirements along with the distance requirements for community ambulation. Distances were measured from and to the closest handicapped parking place to the closest entrance and within the facilities at nine types of sites including supermarkets, drug stores, banks, department stores, post offices, medical offices, superstores, club warehouses and hardware stores. A total of 141 establishments in 15 cities were measured and the distances ranged from $52 \mathrm{~m}$ to 676.8 meters with the shortest distances found at post offices, banks and medical offices. The longest distances were found at hardware, superstore and club warehouses where power scooters were available. Crosswalk distances were measured in four cities curb to curb for two to six lane crosswalks. The time allotted to walk was recorded from the beginning of the "walk" signal to the "don't walk" signal. The time required to walk was also measured for 128 individuals $(\mathrm{n}=32 \geq 65$ years, $\mathrm{n}=$ $96<65$ years) crossing the intersection. The mean gait speed used by the individuals was $1.32(\mathrm{SD} 0.31) \mathrm{m} / \mathrm{s}$. The mean speed required as set by the signals was 0.49 (SD 
$0.20) \mathrm{m} / \mathrm{s}$. The results of the study suggested that $600 \mathrm{~m}$ or more may be distance requirement for full community ambulation and found that speed requirements were set to accommodate the gait speed of older adults ${ }^{6}$.

A study by Duff et al. ${ }^{7}$ reported that global cognition was related to gait speed in older adults with slower walkers performing worse on the cognitive measures and faster walkers performing better. The study was part of the Oklahoma Longitudinal Assessment of Health Outcomes in Mature Adults (OKLAHOMA) Studies and the sample consisted of 675 community dwelling older adults aged 65 and older. Individuals were excluded from the study if they were unable to perform the gait speed test or had comorbidities that would impact cognitive functioning or gait speed including stroke or TIA, head injury or concussion, seizures, PD or brain hemorrhage. The investigators hypothesized that global cognition would be related to gait speed along with other cognitive domains. Global cognition was assessed using the Repeatable Battery for the Assessment of Neuropsychological Status (RBANS) total scale score ${ }^{7}$. The RBANS consists of 12 subtests and is also used to measure immediate and delayed memory along with language, attention and visuospatial/ constructional abilities. The delayed memory index includes four subsets (list recall, list recognition, story recall, and figure recall) that measure recall and recognition. The results can be used to assess cognitive function in individuals from 20-89 years in $\mathrm{age}^{8}$. The index score results were total scale 98.2 (SD 16.1), immediate memory 95.4 (SD 18.0), language 95.6 (SD 11.4), attention 100.2 (SD 16.1), visuospatial/constructional 102.9 (SD 17.7), and delayed memory 98.8 (SD 17.1). Gait speed was measured using a 50-foot course. Participants were asked to walk 25 
feet and return at their usual walking speed. The cohort was divided into three groups based on gait speeds of $<14$ seconds, $14-17$ seconds, and $>17$ seconds. There were significant differences between the groups on age, gender and education. Partial correlations, controlling for age, gender, and education, identified statistically significant relationships $(\mathrm{p}<.01)$ between gait times and the RBANS total and each of the component indexes ${ }^{7}$.

The TUG test is a valid predictor of falls and mobility and measures the time in seconds required for an individual to rise from a chair, walk three meters, return and sit down in the chair ${ }^{9}$. Whitney et al. ${ }^{9}$ studied how the TUG test could be used in association with the Physiological Profile Assessment (PPA) to identify individuals at high risk for falls. The sample consisted of 110 adults aged 63-95 years of age who had fallen in the preceding 6-8 weeks. Fall risk was determined using the PPA and the participants were divided in to low and high fall risk groups based on the score. An Abbreviated Mental Test (AMT) was also administered to evaluate cognitive impairment. The study findings suggested that the TUG test and AMT scores were predictive of high fall risk. The optimal cut-point for differentiating between high and low fall risk of 15 seconds was determined using ROC analysis 9 .

The PADS provides a reliable and valid measure of physical activity for persons with disabilities or chronic health conditions and has been reported to detect intervention related changes in physical activity ${ }^{10}$. Rimmer et al. examined the psychometric properties of the PADS. The study sample consisted of 103 adults aged 30-70 years with disabilities and chronic health conditions. The measures were 46 items in three subscales: exercise, leisure time physical activity and household 
activity. The fitness measures included a graded exercise test and anthropometric measures. The findings supported the internal consistency, reliability and ability of PADS to detect intervention related changes in physical activity indicating that the instrument is useful for monitoring baseline levels and changes in physical activity among persons with disabilities and chronic health conditions ${ }^{10}$.

\section{Resources Cited}

${ }^{1}$ Guralnik, J. M., Simonsick, E. M., Ferrucci, L., Glynn, R. J., Berkman, L. F., Blazer, D. G., ... Wallace, R. B. (1994). A short physical performance battery assessing lower extremity function: association with self-reported disability and prediction of mortality and nursing home admission. Journal of Gerontology, 49(2), M85-M94.

${ }^{2}$ Guralnik, J. M., Ferrucci, L., Simonsick, E. M., Salive, M. E., \& Wallace, R. B. (1995). Lower-extremity function in persons over the age of 70 years as a predictor of subsequent disability. The New England Journal of Medicine, 332(9), 556-561.

${ }^{3}$ Kwon, S., Perera, S., Pahor, M., Katula, J. A., King, A. C., Groessl, E. J., \& Studenski, S. A. (2009). What is a meaningful change in physical performance? Findings from a clinical trial in older adults (The LIFE-P study). Journal of Nutrition, Health and Aging, 13(6), 538-544.

${ }^{4}$ Fritz, S., \& Lusardi, M. (2009). White paper: "walking speed: the sixth vital sign". Journal of Geriatric Physical Therapy (2009), 32(2), 2-5.

${ }^{5}$ Middleton, A., Fritz, S.L., Lusardi, M. (2015). Walking speed: the functional vital sign. Journal of Aging and Physical Activity, 23(2), 314-322.

${ }^{6}$ Andrews, A. W., Chinworth, S. A., Bourassa, M., Garvin, M., Benton, D., \& Tanner, S. (2010). Update on distance and velocity requirements for community ambulation. Journal of Geriatric Physical Therapy, 33(3), 128-134.

${ }^{7}$ Duff, K., Mold, J. W., \& Roberts, M. M. (2008). Walking speed and global cognition: results from the OKLAHOMA Study. Neuropsychology, Development, and Cognition. Section B, Aging, Neuropsychology and Cognition, 15(1), 31-39.

${ }^{8}$ Randolph C., Tierney, M.C., Mohr, E., Chase, T.N. (1998). The repeatable battery for the assessment of neuropsychological status (RBANS): preliminary clinical validity. Journal of Clinical and Experimental Neurophsychology, 20(3), 310-319. 
${ }^{9}$ Whitney, J. C., Lord, S. R., \& Close, J. C. T. (2005). Streamlining assessment and intervention in a falls clinic using the Timed Up and Go Test and Physiological Profile Assessments. Age and Ageing, 34(6), 567-571.

${ }^{10}$ Rimmer, J. H., Riley, B. B., \& Rubin, S. S. (2001). A new measure for assessing the physical activity behaviors of persons with disabilities and chronic health conditions: The physical activity and disability survey. American Journal of Health Promotion, $16(1), 34-45$. 


\title{
Appendix C: Consent Form for Research
}

\section{Longitudinal Study of Communication, Nutrition and Physical Activity}

\author{
Leslie A. Mahler, $\mathrm{PhD}$, Principal Investigator \\ Ingrid Lofgren, $\mathrm{PhD}$, co-Investigator \\ Matthew Delmonico, $\mathrm{PhD}$, co-Investigator \\ CONSENT FORM FOR RESEARCH: Participant \\ Version 3: April 4, 2014
}

The University of Rhode Island

Department of Communicative Disorders

25 W Independence Square, Suite I

Kingston, RI 02881

\section{Purpose of the Consent:}

You have been invited to take part in a research project described below. The purpose of the consent form you are about to read is to provide you with details about the research study and to inform you of your rights if you agree to participate in the study. Your participation is completely up to you. The researcher will explain the project to you in detail. You should feel free to ask questions. If you have more questions later you can call, Dr. Leslie Mahler, the person mainly responsible for this study, at 401874-2490. You may also contact Dr. Ingrid Lofgren at 401-874-5706 or Dr. Matthew Delmonico at 401-874-5440, who are co-Investigators on the study. You must be at least 18 years old, speak English, and have neurological diagnosis of traumatic brain injury, stroke, or Parkinson disease to be in this research project.

\section{Description of the project:}

This is a research project designed to look at communication, nutrition, and physical activity characteristics of adults who have a stroke, traumatic brain injury or Parkinson disease. All evaluations will be conducted at one of two University of Rhode Island locations; in Independence Square on the Kingston Campus at 25 West Independence Way, Kingston or in Independence Square at 500 Prospect Street in Pawtucket.

You are being asked to be in this study because we want to determine the long-term impact of neurological disorders on communication, nutrition, and physical activity. We are looking for 200 people who have a stroke, traumatic brain injury or Parkinson disease to participate in this project. Participation in this study is entirely your choice.

If you decide to take part in this study, you should understand that the evaluations are investigational and you may not experience any benefit from participation. Participation may also involve additional risks as listed in the Potential Risks and Discomforts section. The consent form will help make sure you understand the tasks included in the study before you decide whether you want to take part in the study. You may also quit the study at any time. 


\section{What will be done:}

If you agree to take part in this study, you will be asked to complete up to 11 evaluations over five years. Evaluations will take place every six months. The evaluations will include a variety of tasks such as reading sentences and describing a picture, an assessment of how your muscles move, a cognitive screening, an interview, a clinical swallowing evaluation, and questionnaires regarding swallowing, diet and physical activity. The total time for each evaluation will be approximately $3 \frac{1}{2}$ hours. All evaluations will be conducted in a quiet private room at one of the University of Rhode Island Speech and Hearing Clinic locations (Kingston or Pawtucket).

With your permission, we will request health information from your physician about the following specific items only:

- Date of diagnosis

- Current medications

- Imaging information about where the brain damage is located (if appropriate)

- Stage of Parkinson disease (if applicable)

You will sign a separate form to indicate whether you give your permission to release this health information for the study.

\section{Potential risks and discomforts:}

There are minimal foreseeable risks associated with these evaluations. There have been no reported adverse affects from clinical evaluation of speech and swallowing. There may be some unknown or unanticipated risks, but every precaution will be taken to ensure your personal safety. Even though experienced personnel will obtain the blood samples from a finger prick, there is a chance of discomfort and minor bruising from the finger stick. For physical function testing there is a risk of muscle soreness or other muscle injury as well as skeletal injury but we will minimize these risks by using standard safety practices.

\section{Purpose and benefits of the study:}

The purpose of this study is to describe communication, nutrition, and physical activity behaviors over time to see how they change and affect quality of life. The information obtained is important because it will help us to understand how to provide services to meet the needs of people with neurological diagnoses. This is an investigational study and there is no guaranteed benefit to your communication or nutrition or physical function as a result of participation in this research study. You will receive personal health information such as your height and weight, physical function determined by a physical assessment, your blood lipids such as cholesterol and triglycerides. In addition, you will receive information about your thinking skills and language skills and dietary choices.

\section{Drugs, devices or instruments to be used:}

Drugs will not be used in this study. The equipment for the evaluations include: microphone, sound level meter, tongue blade, a digital tuner, tape recorder, and video cameras. All equipment used to collect cognitive-linguistic and physical function data 
is considered non-invasive. A lancet and capillary tube will be used to obtain the blood sample from a finger prick and the sample will be analyzed on a small portable machine that is on a table.

\section{Cost to participant:}

There is no cost to you for participation in the evaluations. Parking is available for free.

\section{Confidentiality:}

Your part in this study is confidential. Your individual privacy will be maintained in all published and written data resulting from this study. No names of participants will be published or included in written data resulting from this study. Results of this study may be used for purposes of research, educational lectures, and/or professional presentations. When you are entered into the study you will be assigned a code that does not include any identifying information. For example, the first participant will be coded as Long01. The code number will be used on all response forms and in the analysis of the data.

Dr. Mahler and her research team will have sole access to all contact information and evaluation results containing your name. This information will be kept in a locked filing cabinet in a locked office. However, the U.S. Department of Health and Human Services, and the University of Rhode Island Institutional Review Board have the right to inspect all of your records relating to this research for the purpose of verifying data. Because of the need to release information to these parties, absolute confidentiality cannot be guaranteed. Following completion of this project, contact information will be destroyed for those participants who wish, for any reason, not to be contacted in the future. All other information will be archived and kept in a locked filing cabinet with the study results at the University of Rhode Island. All research data will be retained for a minimum of three years following completion of the study and then will be destroyed. Research data will be located in a locked filing cabinet in the principal investigator's locked office.

Cognitive-linguistic evaluations will be audio and video recorded to allow for data analyses. At times these recordings can be useful for teaching students or professionals about the disorders of people with a neurological diagnosis such as yours. Please indicate by signing below whether you give your permission to use your samples for lectures and presentations. Audio and/or videotapes may be used for teaching for up to 3 years after completion of the study. If you agree, you will never be identified by name in the presentations or lectures. Your decision to give permission to use audio and/or video samples in lectures has no impact on your participation in the study.

Yes, I give permission to use audio samples in lectures and presentations.

Yes, I give permission to use video samples in lectures and presentations. 
No, I do not want audio samples used except for research analysis.

No, I do not want video samples used except for research analysis.

\section{In case there is any injury to you during the study:}

If this study causes you any injury, you should immediately contact Dr. Leslie Mahler at (401) 874-2490 or contact the University of Rhode Island Speech and Hearing Clinic at (401) 874-5969. You may also call the office of the Vice President for Research Integrity, 70 Lower College Road, University of Rhode Island, Kingston, RI at (401) 874-4328. If you are injured during an evaluation or during treatment every effort will be made to get you medical attention but you will be responsible for paying for the medical treatment needed.

\section{Decision to quit at any time:}

The decision to take part in this study is up to you. You do not have to participate. If you decide to take part in the study, you may quit and stop participating in this study at any time. You have the right to refuse to answer any question(s) or participate in any procedure for any reason. Deciding not to participate will have no effect on your potential to receive services from a speech-language pathologist. If you wish to quit, simply inform Leslie Mahler at 874-2490 of your decision. If you wish to pursue an alternative treatment instead of completing the study you will be provided with information on how to obtain those services.

\section{Rights and complaints:}

If you are not satisfied with the way this study is performed, you may discuss your complaints with Dr. Leslie Mahler (lmahler@uri.edu; 401-874-2490), Dr. Ingrid Lofgren (ingridlofgren@uri.edu, 401-874-5706), or Dr. Matthew Delmonico (delmonico@uri.edu; 401-874-5440), or you may contact the office of the Vice President for Research for concerns or any questions about your rights as a research subject at: 70 Lower College Road, University of Rhode Island, Kingston, RI at (401) $874-4328$ and speak to them anonymously if you choose.

\section{Authorization:}

Your authorization means that you have read this paper and know the purpose of the study and the possible risks and benefits. It also means you know that being in this study is voluntary and you choose to be in this study. You can also withdraw at any time. Your questions have been answered. Your signature on this form means that you understand the information and you agree to participate in this study.

Signature of Participant Signature of Researcher

$\overline{\text { Participant Typed/printed Name }}$ Researcher Typed/printed name 


\section{Date Date}

Signature of Guardian Signature of Researcher

$\overline{\text { Guardian Typed/printed Name }} \overline{\text { Researcher Typed/printed name }}$

Date Date

Please sign both consent forms, keeping one for yourself. 


\section{Appendix D: Short Physical Performance Battery (SPPB)}

\section{SPPB}

\section{BALANCE SCORING:}

\section{A. Side-by-side-stand}

Held for $10 \mathrm{sec} \square 1$ point

Not held for $10 \mathrm{sec} \square 0$ points

Number of seconds held if less than $10 \mathrm{sec}$ : $\sec$

Not attempted $\square 0$ points

If participant did not attempt test or failed, check why:

Participant could not walk unassisted $\square$

Not attempted, you felt unsafe $\square$

Not attempted, participant felt unsafe $\square$

Participant unable to understand instructions

Other (Specify)

Participant refused $\square$

If 0 points, end Balance Tests

\section{B. Semi-Tandem Stand}

Held for $10 \mathrm{sec} \square 1$ point

Not held for $10 \mathrm{sec} \square 0$ points

Number of seconds held if less than $10 \mathrm{sec}$ : $\sec$

Not attempted $\square 0$ points

If participant did not attempt test or failed, check why:

Participant could not walk unassisted $\square$

Not attempted, you felt unsafe $\square$

Not attempted, participant felt unsafe $\square$

Participant unable to understand instructions $\square$

Other (Specify)

Participant refused $\square$

If 0 points, end Balance Tests

\section{Tandem Stand}

Held for $10 \mathrm{sec} \square 2$ points

Held for 3 to $9.99 \mathrm{sec} \square 1$ point

Held for < than 3 sec $\square 0$ points

Not attempted $\square 0$ points

If participant did not attempt test or failed, check why:

Participant could not walk unassisted $\square$

Not attempted, you felt unsafe $\square$

Not attempted, participant felt unsafe $\square$ 
Participant unable to understand instructions $\square$

Other (Specify)

Participant refused $\square$

D. Total Balance Tests score Comments: (sum points)

GAIT SPEED TEST SCORING:

Length of walk test course: Four meters

\section{A. Time for First Gait Speed Test (sec)}

Time for 4 meters ___ sec

If participant did not attempt test or failed, check why:

Tried but unable $\square$

Participant could not walk unassisted $\square$

Not attempted, you felt unsafe $\square$

Not attempted, participant felt unsafe $\square$

Participant unable to understand instructions $\square$

Other (Specify)

Participant refused $\square$

Aids for first walk None $\square$ Cane $\square$ Other

\section{B. Time for Second Gait Speed Test}

1. Time for 4 meters sec

2. If participant did not attempt test or failed, check why:

Tried but unable $\square$

Participant could not walk unassisted $\square$

Not attempted, you felt unsafe $\square$

Not attempted, participant felt unsafe $\square$

Participant unable to understand instructions $\square$

Other (Specify) $\square$

Participant refused $\square$

Aids for second walk........... None $\square$ Cane $\square$ Other $\square$

What is the time for the faster of the two walks? sec.

If the participant was unable to do the walk: $\square 0$ points

\section{For 4-Meter Walk:}

If time is more than $8.70 \mathrm{sec}: \square \mathbf{1}$ point

If time is 6.21 to $8.70 \mathrm{sec}: \square 2$ points

If time is 4.82 to $6.20 \mathrm{sec}: \square \mathbf{3}$ points

If time is less than $4.82 \mathrm{sec}: \square \mathbf{4}$ points 


\section{CHAIR SCORING:}

\section{Single Chair Stand Test:}

Safe to stand without help YES $\square$ NO $\square$

Participant stood without using arms YES $\square$ NO $\square$ If yes go to repeated stand

Participant used arms to stand YES $\square$ NO $\square$ If yes end test; score as 0 points

Test not completed $\square$ End test; score as 0 points

If participant did not attempt test or failed, check why:

Tried but unable $\square$

Participant could not walk unassisted $\square$

Not attempted, you felt unsafe $\square$

Not attempted, participant felt unsafe $\square$

Participant unable to understand instructions $\square$

Other (Specify) $\square$

Participant refused

\section{Repeated Chair Stand Test}

Safe to stand five times Yes $\square$ No $\square$ If five stands completed record time

Time to complete five stands sec

If participant did not attempt test or failed, circle why:

Tried but unable $\square$

Participant could not walk unassisted $\square$

Not attempted, you felt unsafe $\square$

Not attempted, participant felt unsafe $\square$

Participant unable to understand instructions $\square$

Other (Specify)

Participant refused $\square$

\section{Scoring the Repeated Chair Test}

Participant unable to complete 5 chair stands or completes stands in $>60 \mathrm{sec}: \square 0$ points

If chair stand time is $16.70 \mathrm{sec}$ or more: $\square 1$ points

If chair stand time is 13.70 to $16.69 \mathrm{sec}: \square 2$ points

If chair stand time is 11.20 to $13.69 \mathrm{sec}: \square 3$ points

If chair stand time is $11.19 \mathrm{sec}$ or less: $\square 4$ points

Scoring for Complete Short Physical Performance Battery

Total Balance Test score

Gait Speed Test score points

Chair Stand Test score points

Total Score points (sum of points above) 


\section{Appendix E: Timed Up and Go (TUG) Test}

\section{TIMED UP AND GO}

\section{Time for first TUG test (sec)}

Time: sec

If participant did not attempt test of failed, check why?

Tried but unable

Participant could not walk unassisted

Not attempted, you felt unsafe

Not attempted, participant felt unsafe

Participant unable to understand instructions

Other (specify)

Participant refused

Aids for first walk..............None___ Cane___ Other__

\section{Time for second TUG test (sec)}

Time: $\mathrm{sec}$

If participant did not attempt test of failed, check why?

Tried but unable

Participant could not walk unassisted

Not attempted, you felt unsafe

Not attempted, participant felt unsafe

Participant unable to understand instructions

Other (specify)

Participant refused

Aids for second walk.............None Cane 
DEMOGRAPHICS

NAME: $\quad$ AGE: $\quad$ DATE:
GENDER
$\square$ Male
$\square$ Female
TYPE OF DISABILITY
ASSISTIVE DEVICES (Check all that apply)
$\square$ Walker
$\square$ Braces
$\square$ Cane
$\square$ Wheelchair
USE OF ARMS (Check one)
$\square$ Full
$\square$ Partial
$\square$ No Use
USE OF LEGS
$\square$ Full
$\square$ Partial
$\square$ No Use

Directions: On the following pages are a list of questions related to physical activity and exercise. There are no right or wrong answers and your responses will be kept anonymous. Note that your answers to certain questions in the survey may cause your browser to skip other questions and move to a later item in the survey. Don't worry--this is how the survey was designed in order to save time. Please answer each presented question as accurately and as completely as possible. When you have finished the survey, press the "Submit" button. Your survey responses will be checked and used to create scores reflecting your level of physical activity. A window presenting your scores will then appear. 


\section{NCPAD Physical Activity and Disability Scale}

\section{EXERCISE}

\subsection{Do you currently exercise?}

$\square$ Yes

$\square$ No

\section{IF NO, PLEASE GO TO THE LEISURE ACTIVITY SECTION.}

\subsection{What kind of exercise do you do?}

Directions: List up to four (4) activities below that you do on a regular basis for primary purpose of increasing or maintaining fitness. Aerobics are done for a sustained period of time and result in an increase in your heart rate and breathing rate. Examples include walking, jogging, attending an aerobics class, and bicycling. Strength activities include lifting weights or using elastic bands or weight training machines. Flexibility refers to activities that involve muscle stretching

\section{Activity Type}

Code:

A:

S:

F:
Description

Aerobic Exercise

Strength Exercise

Flexibility Exercise

\section{Activity Type}

(check one)

Activity

Days/Week Minutes/Day Months/Year

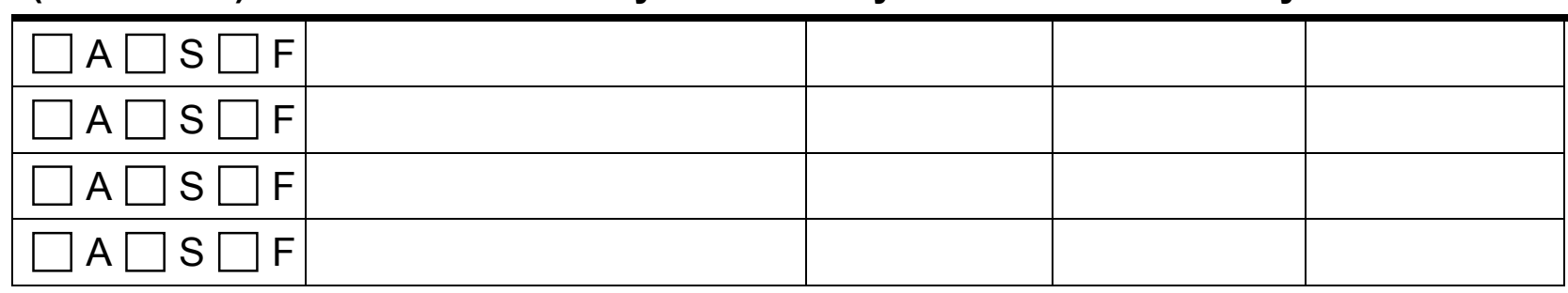

1.02 Have you been exercising for more than one year or less than one year?

$\square$ More than one year

$\square$ Less than one year

1.03 How would you describe the average intensity of your exercise program?

$\square$ Light exercise: Don't sweat or breathe heavily

$\square$ Moderate exercise: Breathe a little harder and may sweat

$\square$ Vigorous: Breathe hard and sweat 
NCPAD Physical Activity and Disability Scale

2. LEISURE ACTIVITY

2.0 Do you engage in leisure time physical activity?

$\square$ Yes

$\square$ No

$\rightarrow$ IF NO, GO TO THE GENERAL ACTIVITY SECTION ON THE NEXT PAGE.

\subsection{What type of activities do you do?}

Directions: List up to four (4) activities below that you do for leisure or recreation. These activities can be done on a regular or irregular basis and may not necessarily result in sustained increases in heart rate and breathing rate. Examples include hiking, boating, skiing, dancing and sports activities. Please indicate whether the activity is an endurance activity or a Non-Endurance activity. Examples of endurance activities include: hiking, tennis, dancing, skiing. Non-endurance activities include boating, softball and horseback riding. Do not list activities here that you already listed under exercise.

\section{Activity Type}

\begin{tabular}{ll} 
Code & Description \\
\hline E & Endurance \\
NE & Non-Endurance
\end{tabular}

\section{Activity Type}

(check one)

Activity

Days/Week Minutes/Day Months/Year

\begin{tabular}{|l|l|l|l|l|}
\hline$\square \mathrm{E} \square \mathrm{NE}$ & & & & \\
\hline$\square \mathrm{E} \square \mathrm{NE}$ & & & & \\
\hline$\square \mathrm{E} \square \mathrm{NE}$ & & & & \\
\hline$\square \mathrm{E} \square \mathrm{NE}$ & & & & \\
\hline
\end{tabular}




\section{NCPAD Physical Activity and Disability Scale}

\section{GENERAL ACTIVITY}

3.00 From Monday through Friday, how many waking hours a day do you usually spend inside your home?

$\square$ Less than 6 hours a day

$\square 6$ to 10 hours a day

$\square$ More than 10 hours a day

3.01 On Saturday and Sunday, how many waking hours a day do you usually spend inside your home?

$\square$ Less than 6 hours a day

$\square 6$ to 10 hours a day

$\square$ More than 10 hours a day

3.02 On average, how many hours a day do you sleep including naps? hours

3.03 On average, how many hours a day are you sitting or lying down, excluding sleeping? hours

3.04 Are most of your indoor household activities done by you or someone Else?

$\square$ Done by you

$\square$ Done by someone else

\section{IF DONE BY SOMEONE ELSE, GO TO QUESTION 3.06.}

3.05 Please list up to four (4) indoor household activities you do and the number of minutes a week you spend on each activity.

\begin{tabular}{|l|l|}
\multicolumn{1}{c|}{ Activity } & Minutes/Week \\
\hline & \\
\hline & \\
\hline & \\
\hline & \\
\hline
\end{tabular}




\section{NCPAD Physical Activity and Disability Scale}

3.06 Do you do any outdoor household activities such as gardening?

$\square$ Yes

$\square$ No

\section{IF NO, GO TO QUESTION 3.08.}

3.07 Please list up to four (4) outdoor household activities you do and the number of minutes a week you spend on each activity.

\begin{tabular}{|l|lll|}
\hline Activity & Days/Week & Minutes/Day & Months/Year \\
\hline & & & \\
\hline & & & \\
\hline & & & \\
\hline & & & \\
\hline
\end{tabular}

3.08 How much assistance do you need to perform activities of daily living such as dressing and bathing?

$\square$ No assistance

$\square$ Some assistance

$\square$ Full assistance 
NCPAD Physical Activity and Disability Scale

\section{THERAPY}

4.00 Do you currently receive physical or occupational therapy?

$\square$ Yes

$\square$ No

$\rightarrow \quad$ IF NO, GO TO EMPLOYMENT SECTION ON THE NEXT

PAGE.

4.01 How many days a week do you receive therapy?

Days.

4.02 How long does each therapy session usually last?

Minutes 


\section{EMPLOYMENT / SCHOOL}

5.00 Are you currently employed / attending school?
$\square$ Employed
$\square$ Retired
$\square$ Not employed
$\square$ Attending school
$\rightarrow$ IF UNEMPLOYED OR RETIRED, GO TO WHEELCHAIR SECTION ON THE NEXT PAGE.

5.01 For most of your work / school day, do you:
$\square$ Move around
$\square$ Stand
$\square$ Sit

5.02 Do you climb any stairs during the work / school day?
$\square$ Yes
$\square$ No

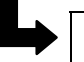

IF NO, GO TO QUESTION 5.04.

5.02a How many flights of stairs do you climb? flights

5.02b How many times a day do you climb the stairs?

5.03 In your transportation to and from work / school, do you get any physical activity?

$\square$ Yes

$\square$ No

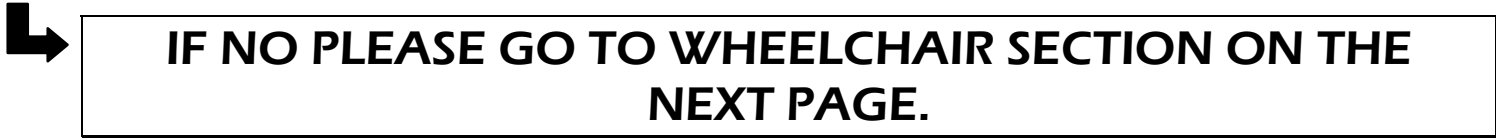

5.04 Please list up to four (4) employment-related physical activities you do and the number of minutes a week you spend on each activity.

\begin{tabular}{|l|l|l|l|}
\hline \multicolumn{1}{c}{ Activity } & Days/Week Minutes/Day & \\
\hline & & & \\
\hline & & & \\
\hline & & & \\
\hline & & & \\
\hline
\end{tabular}




\section{WHEELCHAIR USERS}

\subsection{Do you use a wheelchair?}

$\square$ Yes

$\square$ No

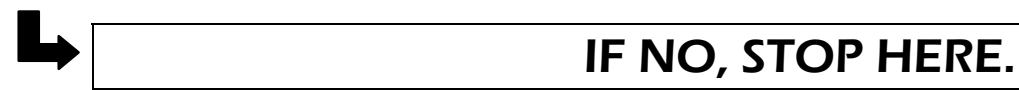

6.01 How many years have you used a wheelchair? years?

6.02 During the time that you are awake, how much time do you: spend in your wheelchair?

$\square$ All day

$\square$ Most of the day

$\square$ A few hours

6.03 What type of wheelchair do you primarily use?

$\square$ Manual wheelchair

$\square$ Powered wheelchair

$\rightarrow$ IF POWERED WHEELCHAIR, STOP HERE.

6.04 Who usually pushes your wheelchair?

$\square$ Myself

$\square$ Someone else

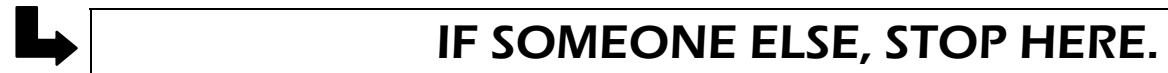

6.05 On average, how many minutes a day do you push yourself in your wheelchair?

$\square$ Less than 60 minutes

$\square$ Sixty minutes or more

Thank you for completing this survey! 
Name

Age

Sex

Education Level

Examiner Date of Testing Ethnicity

Observations:

\begin{tabular}{|c|c|c|c|c|c|c|c|c|}
\hline & $\begin{array}{l}\text { Immediate } \\
\text { Memory }\end{array}$ & $\begin{array}{l}\text { Visuospatial/ } \\
\text { Constructional }\end{array}$ & Language & Attention & $\begin{array}{l}\text { Delayed } \\
\text { Memory }\end{array}$ & \multirow[b]{5}{*}{ Percentile Rank } & $\begin{array}{l}\text { Total } \\
\text { Scale }\end{array}$ & \multirow{5}{*}{$\begin{array}{l}\text { Total Scale } \\
\text { Index Score }\end{array}$} \\
\hline \multicolumn{6}{|l|}{$\begin{array}{l}\text { Index } \\
\text { Score }\end{array}$} & & & \\
\hline \multicolumn{6}{|l|}{$\begin{array}{c}\begin{array}{c}\text { Confidence } \\
\text { Interval } \\
\%\end{array} \\
\end{array}$} & & & \\
\hline \multicolumn{6}{|l|}{ Percentile } & & & \\
\hline \multicolumn{6}{|l|}{ Index Score } & & & \\
\hline 160 & & & 声 & \pm & 4 & $>99.9$ & \pm & 160 \\
\hline 155 & 奉 & 7 & 主 & 主 & 街 & $>99.9$ & 辛 & 155 \\
\hline 150 & 主 & 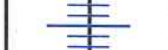 & 奉 & 主 & 表 & $>99.9$ & $F$ & 150 \\
\hline 145 & 奉 & 主 & 姜 & 宔 & 宔 & 99.9 & 曹 & 145 \\
\hline 140 & 奉 & 跓 & 姜 & 奎 & 奎 & 99.6 & 粟 & 140 \\
\hline 135 & 青 & 全 & 表 & 主 & 辛 & 99 & $\frac{1}{+1}$ & 135 \\
\hline 130 & 莑 & 奉 & 邫 & 圭 & $\frac{1}{+}$ & 98 & $\frac{1}{+}$ & 130 \\
\hline 125 & 主 & 全 & 奉 & 奉 & 美 & 95 & $\frac{1}{+}$ & 125 \\
\hline 120 & 青 & 主 & 主 & 辛 & 辛 & 91 & 辛 & 120 \\
\hline 115 & 主 & 表 & 主 & 辛 & 辛 & 84 & 辛 & 115 \\
\hline 110 & 青 & 主 & 主 & 主 & 辛 & 75 & 辛 & 110 \\
\hline 105 & 奉 & 麦 & 主 & 童 & 辛 & 63 & 辛 & 105 \\
\hline 100 & 奉 & 宔 & 主 & 辛 & 辛 & 50 & $\frac{1}{+1}$ & 100 \\
\hline 95 & 主 & 青 & 主 & 主 & 辛 & 37 & 辛 & 95 \\
\hline 90 & 全 & 主 & 主 & 姜 & $\frac{1}{+1}$ & 25 & 辛 & 90 \\
\hline 85 & 青 & 青 & 量 & 主 & 辛 & 16 & 辛 & 85 \\
\hline 80 & 宔 & 宔 & 宔 & 辛 & 辛 & 9 & 辛 & 80 \\
\hline 75 & 奎 & 全 & 主 & 辛 & 主 & 5 & $\frac{1}{+1}$ & 75 \\
\hline 70 & 主 & 主 & 主 & 羔 & $\frac{7}{7}$ & 2 & 辛 & 70 \\
\hline 65 & 奉 & 主 & 美 & 量 & 童 & 1 & 辛 & 65 \\
\hline 60 & 宔 & 封 & 辛 & 辛 & 辛 & 0.4 & 辛 & 60 \\
\hline 55 & 奉 & 主 & $\frac{\text { 章 }}{3}$ & 宔 & 交 & 0.1 & $\frac{1}{+1}$ & 55 \\
\hline 50 & 主 & 奉 & 主 & 主 & $\frac{7}{+1}$ & $<0.1$ & 辛 & 50 \\
\hline 45 & 麦 & 主 & 主 & 主 & 栾 & $<0.1$ & 辛 & 45 \\
\hline 40 & & 主 & 主 & 主 & 主 & $<0.1$ & 辛 & 40 \\
\hline
\end{tabular}




\section{List Learning}

I am going to read you a list of words. I want you to listen carefully and, when I finish, repeat back as many words as you can. You don't have to say them in the same order that I do-just repeat back as many words as you can remember, in any order. Okay?

Trials 2 am going to read the list again. When I finish, repeat back as many words as you can, even if you have already said them before. Okay?

Record responses in order.

Scoring: 1 point for each word correctly recalled on each trial.

\begin{tabular}{|c|c|c|c|c|}
\hline List & Trial 1 & Trial 2 & Trial 3 & Trial 4 \\
\hline \multicolumn{5}{|l|}{ Market } \\
\hline \multicolumn{5}{|l|}{ Package } \\
\hline \multicolumn{5}{|l|}{ Elbow } \\
\hline \multicolumn{5}{|l|}{ Apple } \\
\hline Story & & & & \\
\hline \multicolumn{5}{|l|}{ Carpet } \\
\hline \multicolumn{5}{|l|}{ Bubble } \\
\hline \multicolumn{5}{|l|}{ Highway } \\
\hline \multicolumn{5}{|l|}{ Saddle } \\
\hline \multicolumn{5}{|l|}{ Powder } \\
\hline $\begin{array}{l}\text { Number } \\
\text { Correct }\end{array}$ & & & & \\
\hline
\end{tabular}

\section{Story Memory}

Trial 1

Say I am going to read you a short story. I'd like you to listen carefully and, when I finish, repeat back as much of the story as you can remember. Try and use the same wording, if you can. Okay?

Read the story below, then say Now repeat back as much of that story as you can.

Trial 2

Say I am going to read that same story again. When I finish, I want you to again repeat back as much of the story as you can remember. Try to repeat it as exactly as you can.

Read the story below, then say Now repeat back as much of that story as you can.

Scoring: I point for verbatim recall of bold, italic words or alternatives, shown below in color within parentheses. Record intrusions or variations in the Responses column.

\begin{tabular}{|l|l|l|l|l|}
\hline Story & Responses & $\begin{array}{c}\text { Trial l Score } \\
(0 \text { or } 1)\end{array}$ & $\begin{array}{c}\text { Trial 2 Score } \\
(0 \text { or } 1)\end{array}$ & $\begin{array}{c}\text { Item Score } \\
(0-2)\end{array}$ \\
\hline 1. On Tuesday, & & & & \\
\hline 2. May & & & & \\
\hline 3. Fourth, & & & & \\
\hline 4. in Cleveland, Ohio, & & & & \\
\hline 5. a 3 alarm & & & & \\
\hline 6. fire broke out. & & & & \\
\hline 7. Two & & & & \\
\hline 8. hotels & & & & \\
\hline 9. and a restaurant & & & & \\
\hline 10. were destroyed & & & & \\
\hline 11. before the firefighters (firemen) & & & & \\
\hline 12. were able to extinguish it (put it out). & & & & \\
\hline
\end{tabular}

(Trial $1+$ Trial 2 ) 


\section{Figure Copy}

Fold this page back and present the Figure Copy Drawing Page along with the stimulus. Ask the examinee to make an exact copy of the figure. Tell the examinee that he or she is being timed, but that the score is based on the exactness of his or her copy.

Scoring: 1 point for correctness and completeness (drawing), and 1 point for proper placement. See Appendix 1 in Stimulus Booklet A for complete scoring criteria and scoring examples.

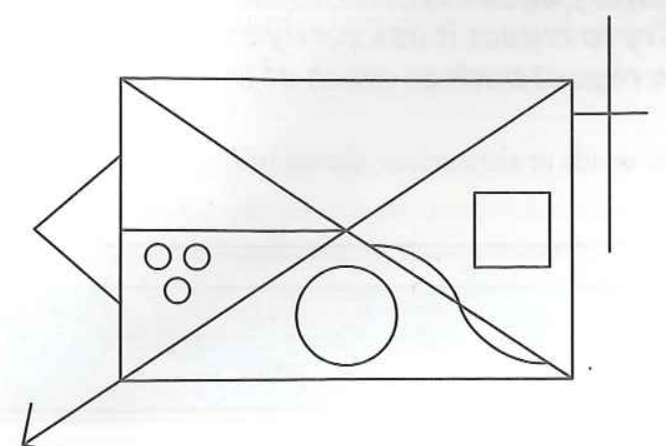

Figure Copy Criteria

(Fold back for use.)

\begin{tabular}{|c|c|c|c|c|}
\hline Item & $\begin{array}{r}\text { Drawing } \\
(0 \text { or } 1)\end{array}$ & $\begin{array}{c}\text { Placement } \\
(0 \text { or } 1)\end{array}$ & $\begin{array}{c}\text { Score } \\
(0,1, \text { or } 2)\end{array} \mid$ & Scoring Criteria \\
\hline 1. rectangle & & & & $\begin{array}{l}\text { Drawing: lines are unbroken and straight; angles } 90 \text { degrees; top/bottom lines } 25 \% \text { longer than sides } \\
\text { Placement: not rotated more than } 15 \text { degrees }\end{array}$ \\
\hline 2. diagonal cross & & & & $\begin{array}{l}\text { Drawing: lines are unbroken and straight and should approximately bisect each other } \\
\text { Placement: ends of lines should meet corners of the rectangle without significant overlap or measurable } \\
\text { distance between the ends of the lines and the corners }\end{array}$ \\
\hline 3. horizontal line & & & & $\begin{array}{l}\text { Drawing: line is unbroken and straight; should not exceed } 1 / 2 \text { the length of the rectangle } \\
\text { Placement: should bisect left side of the rectangle at approximately a right angle and intersect the diagonal cross }\end{array}$ \\
\hline 4. circle & & & & $\begin{array}{l}\text { Drawing: round, unbroken and closed; diameter should be approximately 1/4-1/3 height of rectangle } \\
\text { Placement: placed in appropriate segment; not touching any other part of figure }\end{array}$ \\
\hline 5. 3 small circles & & & & $\begin{array}{l}\text { Drawing: round, unbroken and closed; equal size; triangular arrangement; not touching each other } \\
\text { Placement: in appropriate segment; not touching figure; triangle formed not rotated more than } 15 \text { degrees }\end{array}$ \\
\hline 6. square & & & & $\begin{array}{l}\text { Drawing: must be closed; } 90 \text { degree angles; lines straight and unbroken; height is 1/4-1/3 height of rectangle } \\
\text { Placement: in appropriate segment; not touching any other part of figure; not rotated more than } 15 \text { degrees }\end{array}$ \\
\hline 7. curving line & & & & $\begin{array}{l}\text { Drawing: } 2 \text { curved segments are approximately equal in length and symmetrical; correct direction of curves } \\
\text { Placement: ends of line touch diagonal; do not touch corner of rectangle or intersection of diagonal lines }\end{array}$ \\
\hline 8. outside cross & & & & $\begin{array}{l}\text { Drawing: vertical line of the outside cross is parallel to side of rectangle; }>1 / 2 \text { the height of rectangle; horizontal } \\
\text { line crosses vertical at } 90 \text { degree angle and is between } 20-50 \% \text { of length of vertical line } \\
\text { Placement: horizontal line of outside cross touches rectangle higher than } 2 / 3 \text { the height of rectangle, but below } \\
\text { top; does not penentrate the rectangle }\end{array}$ \\
\hline 9. triangle & & & & $\begin{array}{l}\text { Drawing: angle formed by } 2 \text { sides of triangle is between } 60-100 \text { degrees; sides are straight, unbroken } \\
\text { and meet in a point; distance on vertical side of rectangle subsumed by triangle is approximately } 50 \% \text { of the } \\
\text { height of vertical side } \\
\text { Placement: roughly centered on the left vertical side of the rectangle }\end{array}$ \\
\hline 10. arrow & & & & $\begin{array}{l}\text { Drawing: straight and unbroken; lines forming arrow are approximately equal in length and not more than } \\
1 / 3 \text { length of staff } \\
\text { Placement: must protrude from appropriate corner of rectangle such that staff appears to be continuation } \\
\text { of diagonal cross }\end{array}$ \\
\hline \multicolumn{3}{|c|}{$\begin{array}{r}\text { Total Score } \\
\text { Range }=0-20\end{array}$} & & \\
\hline
\end{tabular}


Present the sample item, and say These two lines down here (indicate) match two of the lines on top. Can you tell me the numbers, or point to the lines that they match? Correct any errors and make sure the examinee understands

Scoring: 1 point for each line correctly identified.

\begin{tabular}{|l|c|c|c|}
\hline \multicolumn{1}{|c|}{ Item } & Responses & Correct Responses & $\begin{array}{c}\text { Score } \\
(0,1, \text { or } 2)\end{array}$ \\
\hline Sample & & 1,7 & \\
\hline 1. & & 10,12 & \\
\hline 2. & & 4,11 & \\
\hline 3. & & 6,9 & \\
\hline 4. & & 8,13 & \\
\hline 5. & & 2,4 & \\
\hline
\end{tabular}

\begin{tabular}{|l|c|c|c|}
\hline \multicolumn{1}{|c|}{ Item } & Responses & Correct Responses & $\begin{array}{c}\text { Score } \\
(0,1,0 \text { r } 2)\end{array}$ \\
\hline 6. & & 1,6 & \\
\hline 7. & & 3,10 & \\
\hline 8. & & 5,8 & \\
\hline 9. & & 1,3 & \\
\hline 10. & & 11,13 & \\
\hline \multicolumn{4}{|c|}{$\begin{array}{r}\text { Total Score } \\
\text { Range }=0-20\end{array}$} \\
\end{tabular}

\section{Picture Naming}

(9) Time Limit:20 seconds/item

Ask the examinee to name each picture. Give the semantic cue only if the picture is obviously misperceived.

Scoring: 1 point for each item that is correctly named spontaneously or following semantic cue.

\begin{tabular}{|l|l|l|l|}
\hline \multicolumn{1}{|c|}{ Item } & Semantic Cue & Responses & $\begin{array}{c}\text { Score } \\
(0 \text { or } 1)\end{array}$ \\
\hline 1. chair & a piece of furniture & & \\
\hline 2. pencil & used for writing & & \\
\hline 3. well & you get water from it & & \\
\hline 4. giraffe & an animal & & \\
\hline 5. sailboat & used on the water (if "boat," query "what kind") & & \\
\hline 6. cannon & a weapon, used in war & & \\
\hline 7. pliers & a tool & & \\
\hline 8. trumpet & a musical instrument ("cornet" okay) & & \\
\hline 9. clothespin & used to hold laundry on a line & & Total Score \\
\hline 10. kite & it's flown in the air & & \\
\hline
\end{tabular}




\section{Semantic Fluency}

Say Now I'd like you to tell me the names of all of the different kinds of fruits and vegetables that you can think of. I'll give you one minute to come up with as many as you can. Ready?

Scoring: 1 point for each correct response.
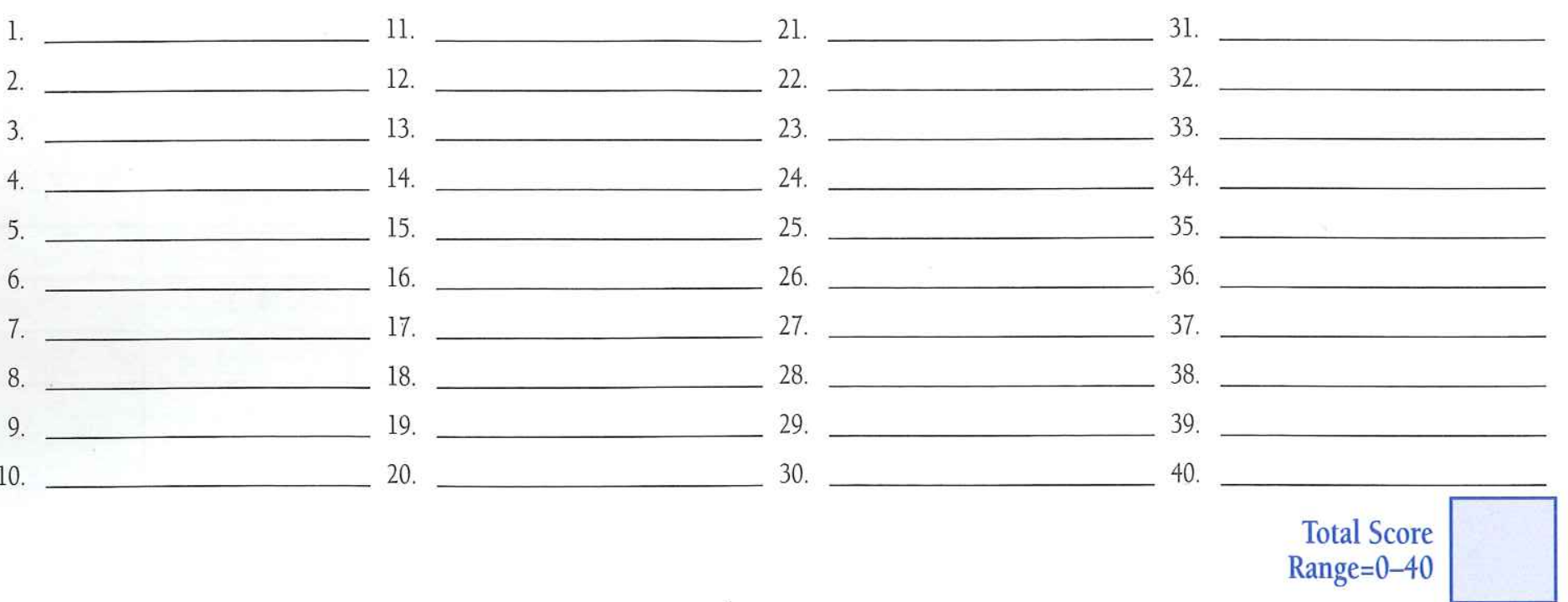

\section{Digit Span}

Say I am going to say some numbers, and I want you to repeat them after me. Okay?

Read the numbers at the rate of 1 per second. Only read the second string in each set if the first string was failed. Discontinue after failure of both strings in any set.

Scoring: 2 points for the first string correct, 1 point for the second string correct, and 0 points for both strings failed.

\begin{tabular}{|l|l|l|l|l|}
\hline Item First String & $\begin{array}{c}\text { String Score } \\
(0 \text { or } 2)\end{array}$ & \multicolumn{1}{|c|}{ Second String } & $\begin{array}{c}\text { String Score } \\
(0 \text { or } 1)\end{array}$ & $\begin{array}{c}\text { Item Score } \\
(0-2)\end{array}$ \\
\hline 1. $4-9$ & & $5-3$ & & \\
\hline 2. $8-3-5$ & & $2-4-1$ & & \\
\hline 3. $7-2-4-6$ & & $1-6-3-8$ & & \\
\hline 4. $5-3-9-2-4$ & & $3-8-4-9-1$ & & \\
\hline 5. $6-4-2-9-3-5$ & & $9-1-5-3-7-6$ & & \\
\hline 6. $2-8-5-1-9-3-7$ & & $5-3-1-7-4-9-2$ & & \\
\hline 7. $8-3-7-9-5-2-4-1$ & & $9-5-1-4-2-7-3-8$ & & \\
\hline 8. $1-5-9-2-3-8-7-4-6$ & & $5-1-9-7-6-2-3-6-5$ & & \\
\hline & & \multicolumn{2}{|c|}{$\begin{array}{c}\text { Total Score } \\
\text { Range=0-16 }\end{array}$} & \\
\hline
\end{tabular}

\section{Coding}

Say Look at these boxes (indicate key). For each one of these marks there is a number that goes with it. Down here there are marks, but no numbers. I want you to fill in the number that goes with each mark.

Demonstrate the first three. Say Now I would like you to fill in the rest of these boxes up to the double lines (indicate) for practice. Correct any errors as they are made. Make sure that the examinee understands the task and has correctly completed the sample items before you begin timing.

Say Now I would like you to continue to fill in the numbers that match the marks. Go as quickly as you can without skipping any. When you reach the end of the line, go on to the next one. Ready? Go ahead.

Redirect the examinee to the task if he or she becomes distracted. If the examinee is unable to comprehend the task, the subtest score is 0 .

Scoring: 1 point for each item correctly coded within 90 seconds (do not score the sample items).

Note: Familiarize yourself with these instructions before administering this subtest. 


\section{List Recall}

ay Do you remember the list of words that I read to you in the beginning? Tell me as many of those words as you can remember now.

Scoring: 1 point for each word correctly recalled.

\begin{tabular}{|c|c|c|}
\hline $\begin{array}{c}\text { List } \\
\text { (Donot read.) }\end{array}$ & Response & $\begin{array}{l}\text { Score } \\
(0 \text { or } 1)\end{array}$ \\
\hline \multicolumn{3}{|l|}{ Market } \\
\hline \multicolumn{3}{|l|}{ Package } \\
\hline \multicolumn{3}{|l|}{ Elloow } \\
\hline \multicolumn{3}{|l|}{ Apple } \\
\hline \multicolumn{3}{|l|}{ Story } \\
\hline \multicolumn{3}{|l|}{ Carpet } \\
\hline \multicolumn{3}{|l|}{ Bubble } \\
\hline \multicolumn{3}{|l|}{ Highway } \\
\hline \multicolumn{3}{|l|}{ Saddle } \\
\hline Powder & & \\
\hline & $\begin{array}{r}\text { Total Score } \\
\text { Range }=0-10\end{array}$ & \\
\hline
\end{tabular}

\section{List Recognition}

Say I'm going to read you some words Some of these words were on that list, and some of them weren't I want you to tell me which words were on the list. For each word, ask Was on the list?

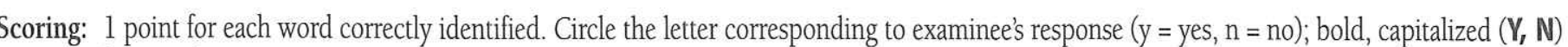
letter indicates correct response.

\begin{tabular}{|c|c|c|c|c|c|c|c|c|c|c|c|}
\hline List & Circle & & List & Circl & & List & Circ & & List & \multicolumn{2}{|c|}{ Circle On } \\
\hline 1. Apple & $Y$ & $\mathrm{n}$ & 6. sailor & $y$ & N & 11. Bubble & $\mathrm{Y}$ & $n$ & 16. Saddle & $\mathrm{Y}$ & $n$ \\
\hline 2. honey & y & N & 7. velvet & $y$ & N & 12. prairie & $y$ & N & 17. Powder & 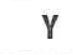 & $n$ \\
\hline 3. Market & $\gamma$ & $\mathrm{n}$ & 8. Carpet & $\mathrm{Y}$ & $n$ & 13. Highway & $\mathrm{Y}$ & $\mathrm{n}$ & 18. angel & $y$ & N \\
\hline 4. Story & $\mathrm{r}$ & $\mathrm{n}$ & 9. valley & $y$ & $\mathrm{~N}$ & 14. oyster & $y$ & $\mathrm{~N}$ & 19. Package & $\mathrm{Y}$ & $n$ \\
\hline 5. fabric & y & N & 10. Elbow & $\mathrm{Y}$ & $\mathrm{n}$ & 15. student & y & N & 20. meadow & $y$ & N \\
\hline & & & & & & & & & $\begin{array}{l}\text { Totata } \\
\text { Rang }\end{array}$ & & \\
\hline
\end{tabular}

\section{Story Recall}

Say: Do you remember that story about a fire that I read to you earlier? Tell me as many details from the story as you can remember now.

Scoring: 1 point for each verbatim recall of bold, italic words or alternatives, shown below in color within parentheses. Record intrusions or variation in the Responses column

\begin{tabular}{|l|l|l|}
\hline Story (Do not read.) & Responses & $\begin{array}{c}\text { Item Score } \\
(0 \text { or } 1)\end{array}$ \\
\hline 1. On Tuesday, & & \\
\hline 2. May & & \\
\hline 3. Fourth, & & \\
\hline 4. in Cleveland, Ohio, & & \\
\hline 5. a 3 alarm & & \\
\hline 6. fire broke out. & & \\
\hline 7. Two & & \\
\hline 8. hotels & & \\
\hline 9. and a restaurant & & \\
\hline 10. were destroyed & & \\
\hline 11. before the firefighters (firemen) & & \\
\hline 12. were able to extinguish it (put it out). & & \\
\hline \multicolumn{2}{r|}{ Range $=0-12$} & \\
\hline
\end{tabular}




\section{Figure Recall}

Say Do you remember that figure that I had you copy? I want you to draw as much of it as you can remember now. If you remember a part, but you're not sure where it goes, put it anywhere. Try to draw as much of it as you can.

Now, present the Figure Recall Drawing Page.

Scoring: 1 point for correctness and completeness (drawing), and 1 point for proper placement. See Appendix 1 in Stimulus Booklet A for complete scoring criteria and scoring examples.

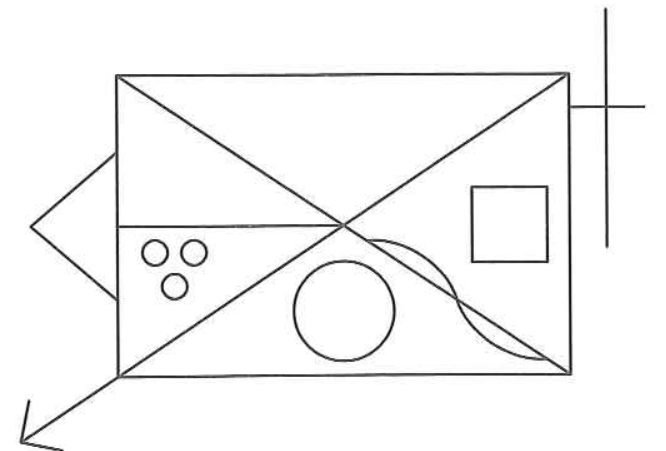

Figure Recall Criteria

(Fold back for use.)

\begin{tabular}{|c|c|c|c|c|}
\hline Item & \begin{tabular}{c|c|c|} 
Drawing \\
$(0$ or 1$)$
\end{tabular} & $\left.\begin{array}{c}\text { Placement } \\
(0 \text { or } 1)\end{array}\right)(($ & $\begin{array}{c}\text { Score } \\
(0,1,0 \mathrm{r} 2)\end{array}$ & Scoring Criteria \\
\hline 1. rectangle & & & & $\begin{array}{l}\text { Drawing: lines are unbroken and straight; angles } 90 \text { degrees; top/bottom lines } 25 \% \text { longer than sides } \\
\text { Placement: not rotated more than } 15 \text { degrees }\end{array}$ \\
\hline 2. diagonal cross & & & & $\begin{array}{l}\text { Drawing: lines are unbroken and straight and should approximately bisect each other } \\
\text { Placement: ends of lines should meet corners of the rectangles without significant overlap or measurable } \\
\text { distance between the ends of the lines and the corners }\end{array}$ \\
\hline 3. horizontal line & & & & $\begin{array}{l}\text { Drawing: line is unbroken and straight; should not exceed } 1 / 2 \text { the length of the triangle } \\
\text { Placement: should bisect correct side of the rectangle at approximately aright tangle and intersect the diagonal cross }\end{array}$ \\
\hline 4. circle & & & & $\begin{array}{l}\text { Drawing: round, unbroken and closed; diameter should be approximately 1/4-1/3 height of triangle } \\
\text { Placement: placed in appropriate segment; not touching any other part of figure }\end{array}$ \\
\hline 5. 3 small circles & & & & $\begin{array}{l}\text { Drawing: round, unbroken and closed; equal size; triangular arrangement; not touching each other } \\
\text { Placement: in appropriate segment; not touching figure; triangle formed not rotated more than } 15 \text { degrees }\end{array}$ \\
\hline 6. square & & & & $\begin{array}{l}\text { Drawing: must be closed; } 90 \text { degree angles; lines straight and unbroken; height is } 1 / 4-1 / 3 \text { height of rectangle } \\
\text { Placement: in appropriate segment; not touching any other part of figure; not rotated more than } 15 \text { degrees }\end{array}$ \\
\hline 7. curving line & & & & $\begin{array}{l}\text { Drawing: } 2 \text { curved segments are approximately equal in length and symmetrical; correct direction of curves } \\
\text { Placement: ends of line touch diagonal; do not touch corner of square or intersection of diagonal lines }\end{array}$ \\
\hline 8. outside cross & & & & $\begin{array}{l}\text { Drawing: vertical line of the outside cross is parallel to side of rectangle; }>1 / 2 \text { the height of rectangle; horizontal } \\
\text { line crosses vertical at } 90 \text { degree angle and is between } 20-50 \% \text { of length of vertical line } \\
\text { Placement: horizontal line of outside cross touches rectangle higher than } 2 / 3 \text { the height of rectangle, but below } \\
\text { top; does not penetrate the rectangle }\end{array}$ \\
\hline 9. triangle & & & & $\begin{array}{l}\text { Drawing: angle formed by } 2 \text { sides of triangle is between } 60-100 \text { degrees; sides are straight, unbroken } \\
\text { and meet in a point; distance on vertical side of rectangle subsumed by triangle is approximately } 50 \% \text { of the } \\
\text { height of vertical side } \\
\text { Placement: roughly centered on the vertical side of the rectangle }\end{array}$ \\
\hline 10. arrow & & & & $\begin{array}{l}\text { Drawing: straight and unbroken; lines forming ạrow are approximately equal in length and not more than } \\
1 / 3 \text { length of staff } \\
\text { Placement: must protrude from appropriate corner of rectangle such that staff appears to be continuation } \\
\text { of diagonal cross }\end{array}$ \\
\hline & & & & \\
\hline
\end{tabular}




\section{Supplemental Discrepancy Analysis Page}

Index Differences

\begin{tabular}{|c|c|c|c|c|c|}
\hline Score 1-Sco & Score 1 & Score 2 & Difference & $\begin{array}{c}\text { Statistical } \\
\text { Significance } \\
\text { Level }\end{array}$ & $\begin{array}{c}\begin{array}{c}\text { Frequency of } \\
\text { Difference in } \\
\text { Standardization } \\
\text { Sample }\end{array} \\
\end{array}$ \\
\hline \multicolumn{6}{|c|}{ Immediate Memory_Visuospatial/Constructional } \\
\hline \multicolumn{6}{|l|}{ Immediate Memory-Attention } \\
\hline \multicolumn{6}{|l|}{ Immediate Memory-Language } \\
\hline \multicolumn{6}{|c|}{ Immediate Memory_Delayed Memory } \\
\hline \multicolumn{6}{|l|}{ Immediate Memory_Total Scale } \\
\hline \multicolumn{6}{|c|}{ Visuospatial/Constructional-Attention } \\
\hline \multicolumn{6}{|c|}{ Visuospatial/Constructional-Language } \\
\hline \multicolumn{6}{|c|}{ Visuospatial/Constructional-Delayed Memory } \\
\hline \multicolumn{6}{|c|}{ Visuospatial/Constructional-Total Scale } \\
\hline \multicolumn{6}{|l|}{ Attention-Language } \\
\hline \multicolumn{6}{|l|}{ Attention-Delayed Memory } \\
\hline \multicolumn{6}{|l|}{ Attention-Total Scale } \\
\hline \multicolumn{6}{|l|}{ Language-Delayed Memory } \\
\hline \multicolumn{6}{|l|}{ Language-Total Scale } \\
\hline Delayed Memory-Total Scale & & & & & \\
\hline
\end{tabular}




\section{Score Conversion Page}

I. Immediate Memory

1. List Learning Total Score.

2. Story Memory Total Score

II. Visuospatial/Constructional

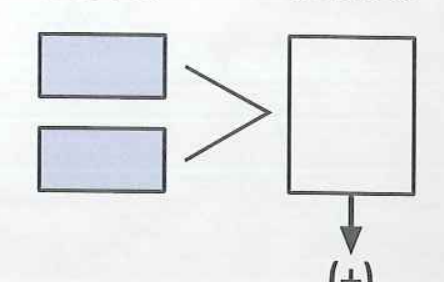

3. Figure Copy Total Score...

4. Line Orientation Total Score

\section{Language}

5. Picture Naming Total Score.

6. Semantic Fluency Total Score

IV. Attention

7. Digit Span Total Score . 8. Coding Total Score.

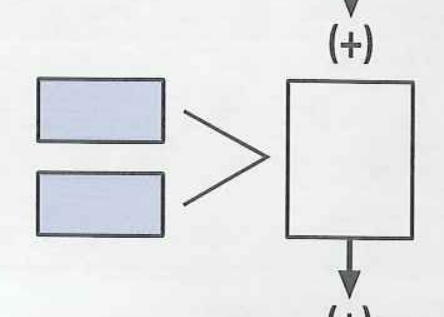

\section{Delayed Memory}

9. List Recall Total Score..........

10. List Recognition Total Score..

11. Story Recall Total Score.......

12. Figure Recall Total Score ...

12. Figure Recall Total Score ....

Note. Use Appendix 2 in Stimulus Booklet A to convert total scores to index scores and sum of index scores to total scale.
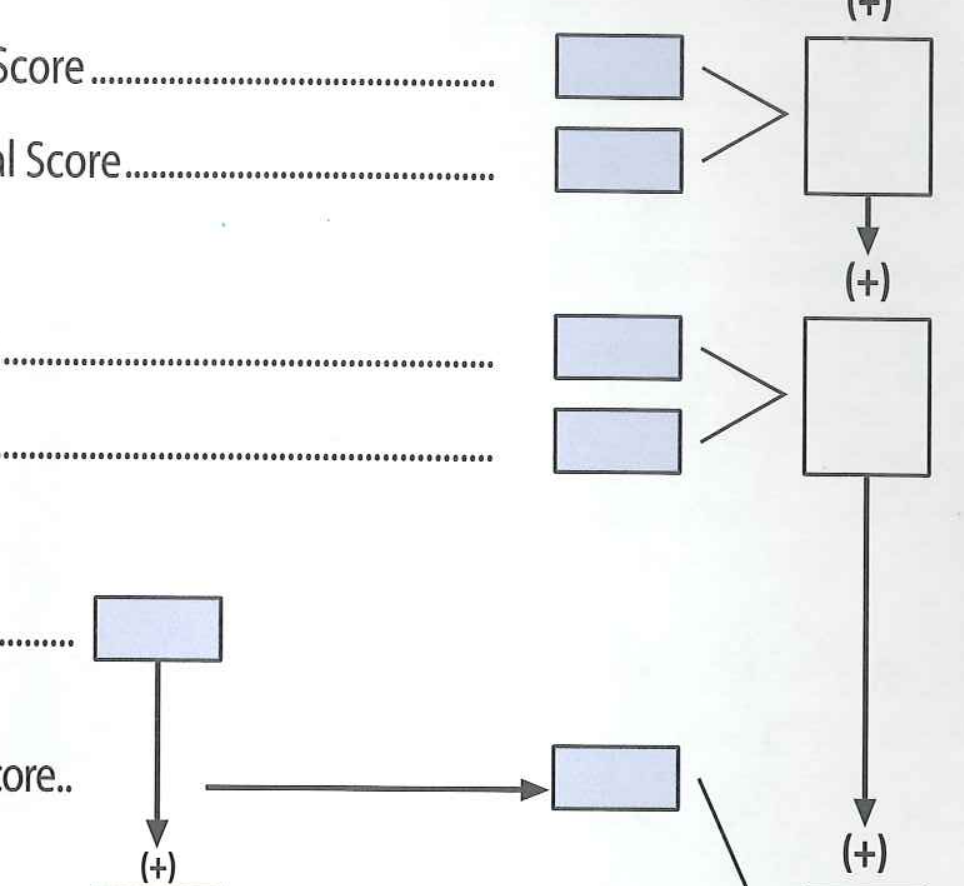

$\underset{\substack{+(+)}}{+}$

$\stackrel{+}{=}$

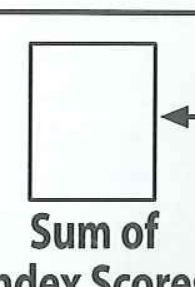

Index Scores

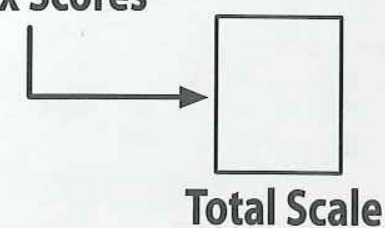




$$
\begin{array}{|c|c|c|c|c|c|c|c|c|}
\hline \subset & ヘ & = & \lrcorner & \curlyvee & \supset & + & \perp & \vdash \\
\hline 1 & 2 & 3 & 4 & 5 & 6 & 7 & 8 & 9 \\
\hline
\end{array}
$$

SAMPLE

$$
\begin{aligned}
& \begin{array}{|l|l|l|l|l|l|l|l|l||l|l|l|l|l|}
\hline= & \vdash & \subset & \wedge & + & \lrcorner & \perp & \supset & \vee & = & \vdash & \wedge & \supset & + \\
\hline
\end{array} \\
& \begin{array}{|l|l|l|l|l|l|l|l|l|l|l|l|l|l|}
\hline \perp & \supset & \vee & \vdash & = & \wedge & \subset & + & \lrcorner & \wedge & \perp & \subset & + & \lrcorner \\
\hline
\end{array} \\
& \begin{array}{|l|l|l|l|l|l|l|l|l|l|l|l|l|l|}
\hline \supset & \vdash & \wedge & = & \vee & \subset & \lrcorner & + & \perp & = & \supset & \wedge & \vdash & \subset \\
\hline
\end{array} \\
& \begin{array}{|c|c|c|c|c|c|c|c|c|c|c|c|c|c|}
+ & \subset & \vdash & \lrcorner & = & \vdash & + & ヘ & \supset & \subset & \lrcorner & \perp & + & \vdash \\
\hline
\end{array} \\
& \begin{array}{|l|l|l|l|l|l|l|l|l|l|l|l|l|l|}
\hline \subset & + & \vdash & \supset & \wedge & = & \perp & \lrcorner & \subset & = & + & \vee & \perp & \wedge \\
\hline
\end{array} \\
& \begin{array}{|l|l|l|l|l|l|l|l|l|l|l|l|l|l|}
\hline \widehat{ } & = & \lrcorner & \vdash & + & \vee & \perp & \lrcorner & ヘ & \supset & \vee & \perp & \subset & \lrcorner \\
\hline
\end{array} \\
& \begin{array}{|l|c|c|c|c|c|c|c|c|c|c|c|c|c|}
\hline+\subset & \lrcorner & \supset & \wedge & = & \subset & + & \perp & \vee & \lrcorner & \wedge & \supset & = \\
\hline
\end{array}
\end{aligned}
$$

